\title{
Impact of Advanced Aerodynamic Technology on Transportation Energy Consumption
}

\author{
Richard M. Wood \\ SOLUS - Solutions and Technologies
}

Copyright $@ 2004$ SAE International

\begin{abstract}
An assessment of the role of fluid dynamic resistance and/or aerodynamic drag and the relationship to energy use in the United States is presented. Existing data indicates that $16 \%$ of the total energy consumed in the United States is used to overcome aerodynamic drag in transportation systems. Application of existing pressure drag reduction technologies to all ground vehicles within the United States will reduce yearly energy costs by 20 billion dollars.
\end{abstract}

\section{INTRODUCTION}

Three dominant forces in nature that influence our way of life are; gravity, fluid-dynamics (i.e., wind and water forces), and solid mechanics (i.e., earthquakes). It is argued that after gravity, fluid-dynamics is nature's most prevalent force on earth. We spend our life interacting with a variety of fluids from the air we breath and water we drink to the storms we shelter from. Fluid-dynamic forces have a significant influence on transportation, recreation, and sport; and greatly influence the energy consumption of our transportation systems, manufacturing processes, and heating and cooling needs [1-3], with transportation consuming the largest portion of energy within the United States. A review of available data shows that the majority of the transportation energy is used to overcome fluid dynamic resistance and/or aerodynamic drag.

A review of the literature show that previous discussions of aerodynamic drag have been either discipline focused $[4,5]$. such as aircraft or ground vehicles; or in order to accentuate the unique character and features of a research area. The present discussion will review the general topic of fluid-dynamic resistance and/or aerodynamic drag for transportation systems and relate these observations to energy consumption. The discussion of energy consumption provides a direct connection to the economic impact of the technologies that are capable of reducing aerodynamic drag and it provides a technical connection to other disciplines and industries that benefit from aerodynamic drag reduction technologies.

The relationship between aerodynamic drag and energy use in the United States (US) can be obtained by reviewing data from the Department of Transportation (DOT) and the Department of Energy (DOE) [1-3, 6-11]. An analysis of the DOE and DOT energy data coupled with a fundamental understanding of the role of fluiddynamic resistance on transportation allows for estimates of energy use in the United States (U.S.).

All transportation systems involve either the movement of solid structures through fluids or the movement of fluids past solid structures (i.e., aerodynamics, hydrodynamics, and fluid-dynamics). Overcoming the aerodynamic/hydrodynamic drag and fluid-dynamic resistance associated with transportation constitutes a significant portion of the energy consumed within the United States, as noted above. However, there has never been a national effort focused on the reduction of aerodynamic drag and fluid-dynamic resistance.

The importance of this matter continues to grow as is evident by the growing energy imbalance within the U.S. [1, 2]. At present, the U.S. consumes 35\% more energy than it produces; and by 2020, the imbalance will increase to $65 \%$. A more dramatic trend is noted for the transportation sector where U. S. oil consumption exceeded the U. S. oil production by $85 \%$ in 2004 and it is projected that by 2020 oil consumption will exceed U. S. production by $140 \%$. To address these issues, the Department of Transportation (DOT) [11] and the Department of Energy (DOE) [1] have a number of programs investigating a variety of technologies including American fuels and advanced manufacturing 
processes. However, it is clear that solving the U.S. energy problem requires technical contributions from all elements of the scientific and engineering sectors.

An objective of this paper is to raise the awareness if these issues within the scientific community. To this end, a discussion of aerodynamic drag reduction research is presented and example aerodynamic drag and fluid-dynamic resistance reduction technologies that have crossed over from one discipline to another are discussed. A second objective of this paper is to develop an energy-based argument for the discussion of drag and drag management issues in order to bring together a portion of the diverse array of scientific and engineering resources within the United States.

\section{DISCUSSION}

\section{AERODYNAMIC DRAG}

To provide structure to the discussion of aerodynamic drag and energy, the interrelationships between fundamental forces, areas of application, types of flow, control effectors, and flow phenomena affected are presented in figure 1. The table of figure 1 is based upon a review of the literature in the areas of aerodynamics [4, 12-15], transportation [5, 18-20], boundary layer flows [16, 17-27], chemical engineering $[28,29]$, and industrial engineering [30-37]. This review identified transportation, industrial, and residential /commercial as the primary areas of application for fluid resistance (aerodynamic/hydrodynamic drag) reduction technologies. The sub-areas listed under each primary area of application are organized in descending order of energy use. The types of flow that occur in the application areas are extremely diverse and are characterized by changes in boundary layer state with either organized or random separation for a gas, liquid, or a multi-phase flow medium. Drag reduction technologies (e.g. effectors) that are used in the areas of application to manage these diverse flows are focused on changes to the surface of the solid body or modify the local flow field by adding or removing mass, temperature, or energy. Although there is a significant amount of work in the areas of boundary layer control for drag reduction the primary effector types remain focused on changes to the body surface. The impact of each technology concept is the modification of both surface and flow field properties in order to alter the body forces or to manage the flow mixing, motion, and noise.

A list of representative aerodynamic drag reduction and/or flow-control effectors for the three areas of application, are provided in figure 2. The information contained in figure 2 was extracted from the available literature and show that only the transportation area utilizes all ten (10) types of effectors identified in figure 1. In contrast, the Industrial area utilizes eight (8) of the ten (10) and the Residential/Commercial area is the most limited with three (3) types of flow control effectors. The number and diversity of drag reduction effectors in each of the three application areas correlates directly with the energy consumed in each area to overcome aerodynamic drag. The control effectors employed in the Transportation area are evenly distributed between skin-friction and pressure drag reduction, whereas, the effectors in the Industrial area are dominated by skinfriction types.

To provide additional insight into the aerodynamic drag reduction issues facing the community, a brief review of the transportation area is presented. The transportation area is selected for this expanded discussion because it is the largest energy user within the U. S., and it is also the area that is most dependent upon drag reduction for economic success. As shown in figure 1, the transportation area is comprised of ground vehicles, aircraft, watercraft, rail, and pipe systems, with ground, air, and water vehicles comprising $94 \%$ of all energy used by transportation in the U. S [11]. Note, ground vehicles use more than six times the energy than the combination of aircraft and watercraft in the U. S.

A top-level drag breakdown for the various transportation vehicles is presented in figure 3 . The chart shows the relative magnitude of pressure drag and skin-friction drag for each vehicle type. This information shows that ground vehicle drag is dominated by pressure drag and aircraft drag and water vehicle drag is comprised of an equal amount of pressure and skin-friction drag. To complete the analysis of the transportation area requires an assessment of the energy used to overcome drag, relative to the total energy used by the vehicle, see figure 4 . A review of the available data $[10,11]$ shows that ground vehicles use approximately $50 \%$ of their energy overcoming aerodynamic drag whereas both aircraft and watercraft use $90 \%$ of their energy consumption to overcome drag, see figure 4 . By combining the data from figure 3 and 4 it can be shown that transportation drag is comprised of $40 \%$ skin friction drag and $60 \%$ pressure drag, see figure 5 .

\section{ENERGY USAGE}

Presented in figure 6 is a summary of the energy consumption in the U. S. for 2000 [1-3]. The figure shows the various sources of energy and the relative magnitude of the imported and exported energy products. The data are presented as quadrillion (QUAD) British thermal units (BTU). A review of the data of figure 5 [1-3] shows that the largest consumer of energy is transportation, with $99 \%$ of the transportation energy derived from petroleum. 


\section{$\underline{\text { Transportation }}$}

The transportation area uses $27 \%$ of all energy consumed in the U.S., and the dominant transportation sector is ground vehicles as shown in figure $7[10,11]$. It is interesting to note that the energy use data, see figure 7 , for ground vehicles shows that cars and light duty vehicles used $350 \%$ more energy than heavy vehicles, however, a review of the DOT statistics [10] show there are 3,330\% more cars and light duty vehicles than heavy vehicles. These data highlight the dramatic difference in vehicle drag and the miles driven per vehicle between light and heavy vehicles. A similar analysis can be made between all ground vehicles and aircraft. The data of figure 7 show that ground vehicles used $1,000 \%$ more energy than aircraft and yet surprisingly there are $74,300 \%$ more ground vehicles than aircraft. These data can be used to highlight the relative payoff for drag reduction efforts based upon vehicle types. It is clear that the large energy use by an individual aircraft provides an incentive to the community to focus their drag reduction efforts in this area. In a similar fashion, the analysis indicates that the drag reduction focus for ground vehicles should be directed towards large trucks and other heavy vehicles that travel a large number of miles each year.

Combining the data from figures 3,4 , and 7 allows the results presented in figure 5 to be weighted by fuel usage, see figure 8 . The data of figure 8 show that transportation drag is comprised of $30 \%$ skin friction drag and $70 \%$ pressure drag. An extension of this analysis is shown in figure 9 in which the drag breakdown analysis is limited to only the ground transportation sector. The data of figure 9 shown that ground transportation drag is $20 \%$ skin friction drag and $80 \%$ pressure drag. This simple analysis strongly suggests that future drag reduction efforts should focus primarily on pressure drag reduction technologies.

Additional motivation for drag reduction efforts can be drawn from a review of the historical trend in energy usage for the transportation area[10,11]. The data show that transportation energy demands, which are 99\% dependent on oil, exceeded U.S. production levels in the 1980s and at present the transportation area consumes $85 \%$ more energy (oil) than is produced in the U.S. The chart also shows that the energy (oil) shortfall will continue to increase and by 2020 , consumption will be $140 \%$ greater than production.

A review of the ground transportation sector data of figure 10 shows that the energy demands of automobiles will remain constant. However, there are dramatic increases in both light and heavy truck energy demands. These projected detrimental energy trends should be viewed as an opportunity for aerodynamic drag reduction efforts. A focused effort on heavy ground vehicles, which have the largest aerodynamic drag levels and have the greatest miles driven per vehicle, will provide a significant payoff in energy savings even with small drag reductions.

\section{DESIGNING THE FUTURE}

It is envisioned that by focusing on aerodynamic and fluid-dynamic issues in the transportation area creates the opportunity for significant synergistic interactions among other subject areas. These interactions have the potential to support the development of energy efficient technologies that will dramatically improve our environment, lead to the development of new energy sources, and culminate in radically improved transportation, industrial and manufacturing processes, and systems

Many of the "best practices" and "advanced technologies" in use within the aerodynamics and fluiddynamics disciplines are also hindered by their reliance on past understanding and biases. A survey of the literature indicates that even though there are significant resources expended in the subject topic area, they are spread among a diverse array of technology development activities and among a myriad of government agencies, academia, industries, and professional organizations. These research efforts operate in a competing mode resulting in a fragmented technology development effort. To achieve success the vast array of organizations and discipline research efforts in aerodynamics, transportation, hydrodynamics, wind engineering, environmental sciences, chemistry, medical engineering, combustion, manufacturing, etc. must be brought together under a framework that is focused on a single theme.

Specific goals may be established such as; pressure drag and viscous drag reduction goals of $50 \%$. Another objective is to define consistent drag reduction research "best practices" and goals across all research disciplines and implementation of the processes must be performed in a manner that ensures a significant portion of the success is portable.

It is estimated that $25 \%$ of the total energy consumed in the U.S. is used to overcome drag. Of this, $16 \%$ is attributed to Transportation and 9\% is related to Industrial and Residential/Commercial energy consumption. If the drag reduction goals discussed above are realized, a $7.85 \%$ total energy savings would be achieved. This energy savings is comprised of $5.6 \%$ from transportation (note: it is approximated that a $50 \%$ drag reduction results in a 35\% energy savings) and $2.25 \%$ from the combination of Industrial and Residential/ Commercial (note: it is approximated that a $50 \%$ drag reduction results in a $25 \%$ energy savings). This energy savings correlates to a yearly cost savings in the $\$ 30$ Billion dollar range. 


\section{Drag Reduction Technologies}

To achieve success both skin-friction drag [24, 38-68] and pressure drag [5, 18-21, 69-101] reduction technologies must be developed, applied, and transferred across discipline lines. However it has been shown that the dominant consumer of energy is the transportation sector and more specifically the ground transportation sector. It has been further shown that the majority of the energy consumed by ground transportation drag is used to overcome pressure drag. For these reasons the following section will focus on pressure drag reduction technologies for ground vehicles.

The discussion of pressure drag reduction technologies will follow the outline presented in figure 2. Specifically, pressure drag reduction technologies will be shown for surface shaping for attached flow in figure 11, surface shaping for separated flow in figures 12 and 13, surface motion in figure 14, surface permeability in figure 15, mass addition in figure 16, and energizing the external flow in figures 17-19. All of the ground vehicle drag reduction technologies presented in figures 11-19 have their lineage to the aircraft community.

Surface shaping technologies fall into two categories, those directed at attached flow and those directed at separated flow. The attached flow technologies are the most mature and are shown in figure 11 [107]. Several flying wing aircraft are depicted on the left of figure 11 to represent the attached flow design concept for aircraft. For ground vehicles figure 11 show the evolution of aerodynamic shaping from a box shape with sharp corners to a highly contoured vehicle with rounded corners. This attached flow shaping is the most fundamental design technology and has been shown to provide very large drag reduction benefits that exceed $30 \%$. This technology is the accepted standard in both the aircraft and ground vehicle industries.

The first separated flow surface shaping technology is base plates which are used to control base drag, see figure 12 . The base plate technology was initially developed in 1966 by Bearman to reduce the base drag of blunt trailing edge airfoils $10 \%[94,95]$. This technology then found its way to ground vehicles in 1987 as documented in reference 19 providing a $15 \%$ drag reduction.

The second separated flow surface shaping technology is shown in figure 13 and employs a trapped vortex to provide drag reduction. The aircraft based trapped vortex concept was initially demonstrated by Kasper in 1974 [108] and has been subsequently applied to a wide variety of airfoils and three-dimensional wings. The technology was extended to ground vehicles in 2003 by Wood and Bauer [109]. The ground vehicle application was designed to treat the gap flow between the tractor and trailer. The concept traps a series of vortices on the front face of the trailer in order to generate a thrust force. The ground vehicle trapped vortex technology has demonstrated a drag reduction of $30 \%$.

In the area of pressure drag reduction for ground vehicles the work of Modi [69] and Englar [20] are noteworthy for transferring the technology from aircraft to ground vehicles, see figures 14 , and 15 , respectively. Modi also has transferred the technology out of the transportation area as documented in reference 69 . There are similarities in the work of Modi and Englar in that they both add momentum to the flow in order to eliminate/control flow separation. Modi employs a moving surface (see figure 14) to achieve this end whereas Englar uses air injection (figure 15). Both have achieved significant drag reductions on the order of $30 \%$ with their associated technologies.

As shown in figure 16, the passive porosity work of Bauer and Wood [101] employs a passive feedback mechanism to control flow separation on a blunt base and produces a drag reduction of $15 \%$. It is interesting to note that passive porosity technology has its roots in the Industrial area where it was used for vortex shedding control on smoke stacks. This technology was transferred to the aerodynamic community to be used as a liner for wind tunnel walls. Another evolution of the technology occurred in the 1980s and produced a drag reduction concept as documented by the work of Bauer [101].

The final technology area is the use of passive devices to energize the external flow field in order to reduce or eliminate flow separation. Three technologies are presented in this area. Figures 17 and 18 show concepts that employ vortex flows and figure 19 show the use of a nozzle to increase the velocity and momentum of an unsteady flow field.

Vortex generators technology is a much more mature, diverse, and far reaching in acceptance [61], see figure 17. Vortex generators were initially developed and applied to aircraft but have been accepted throughout the transportation and Industrial areas. Vortex generators can be found on aircraft, ground vehicles, and watercraft and in diffusers and heat exchangers. Vortex generators are designed as both active and passive devices, mechanical and pneumatic devices, and operate on the boundary layer flow. Representative drag reduction benefits for aircraft have exceeded $20 \%$ but only marginal results have been realized on ground vehicles.

The second vortex based technology is the vortex strake as shown in figure 18. The vortex strake is used as a flow control and lift enhancement device for aircraft as noted by the F-18 on the left side of figure 18 [110]. The vortex strake technology was extended to ground vehicles by Wood and Bauer [109]. For the ground 
vehicle application strakes were installed on the aft portion of a trailer in order to energize and direct the flow exiting the trailer and flowing into the bluff base wake region. This concept has shown drag reductions greater than $10 \%$.

The final technology is related to the use of a contraction cone to add momentum to the unsteady undercarriage flow and to direct the high momentum flow into the trailing wake, see right side of figure 19. The design of the high momentum mud flap concept [109] is taken from low speed wind tunnel design [111] technology, specifically the design of the contraction cone as noted on the left side of the figure. In wind tunnel design, care is taken to minimize the pressure gradients at the start and the end of contraction and to minimize separation in the corners. For the ground vehicle drag reduction concept the contraction cone is a two dimensional design, where the trailer under surface and the ground form parallel sides. The two vertical sides are carefully designed to minimize flow separation while increasing the undercarriage flow velocity. This technology has shown drag reduction of greater than $10 \%$.

Additional extensions/crossovers of each of these technologies is possible with clear applications to diffusers, ducting, pipes, valves, and heat exchangers to name a few. There are also other aerodynamic technologies such as thrust vectoring [85] self activating flaps [72], oscillating flow spoilers [74], and pneumatic spoilers [82] that would improve the performance of ground vehicles as well as various industrial and manufacturing systems.

To complete the discussion of drag reduction technologies a few comments are offered on skin friction drag reduction. A literature survey of the skin-friction drag area highlights the diversity and magnitude of the research being performed by a broad cross section of Industries and agencies [24, 38-69]. The area of skinfriction drag reduction is typically divided into two efforts, those focused on maintaining a laminar boundary layer and efforts reducing the turbulent boundary-layer skinfriction drag. It is beyond the scope of this paper and the author to address the diversity and complexity of this topic area other than to recognize that it is a highly competitive area and it appears to be driven by economic factors that dominate the Industrial area within the U.S.

However, there are several examples worth noting. One of the skin friction drag cross over technologies is riblets [65]. Riblets were conceived from observations of nature [102-105], specifically the skin of a shark, and they were originally developed for aircraft applications. They have found their way onto watercraft and into pipes and ducts. It is interesting to note that they have not achieved universal success in the aerospace community but a version of the technology is used in the Industrial area for pipe flows [24].

Other skin friction drag reduction technologies are laminar flow control with boundary layer removal or wall cooling [66], turbulent boundary layer polymer addition and bubble injection [59], and wall oscillation and compliant walls [41].

\section{Drag Reduction Assessment}

The previous discussion has argued that significant reductions in energy usage can be achieved by focusing drag reduction efforts on ground transportation pressure drag. To provide additional focus to this argument three summary charts are presented in figures 20 through 22 . Figure 20 presents a matrix that show the recommended vehicle classes that would benefit from an application of the various drag reduction technologies. The chart indicates that only surface shaping and energy addition technologies are applicable to all ground vehicle classes. Surface motion, surface permeability, and mass addition technology are more restrictive due to increased complexity, cost and maintenance.

A simplistic cost benefit analysis of the technologies for each vehicle class is presented in figure 21 . These results are presented as the time in years for a return on investment $(\mathrm{ROI})$ required to install each technology type on the subject vehicle class. The information contained in figure 21 show that the two surface shaping technologies and the energy addition technologies provide an $\mathrm{ROI}$ of less than one year. The next most promising technology type is the mass-addition concept that has an ROI of less than two years.

Presented in figure 22 are the final technology assessment chart that shows the drag reduction potential and thus the fuel savings available for two of the three most promising technology types. Because the attached flow surface shaping technology is viewed as an industry standard it is not included in the summation of additional fuel saving benefit. Due to the limited application and long term payback the benefits associated with surface motion, surface permeability, and mass addition are not included. The information of figure 22 shows that significant fuel savings can be achieved for each vehicle class. The chart show fuel savings of 15 $25 \%$ for heavy trucks, $10-14 \%$ for light trucks , and $4-$ $10 \%$ for automobiles can be realized if separated flow surface shaping and energy addition technologies are applied. These technologies have the potential to reduce ground vehicle fuel consumption within the United States by more than $10 \%$ and provide a cost savings of 20 billion dollars a year. 


\section{CONCLUDING REMARKS}

An assessment of the role of fluid dynamic resistance and/or aerodynamic drag on transportation energy use in the United States is presented. Existing data indicates that up to $25 \%$ of the total energy consumed in the United States is used to overcome aerodynamic drag, $27 \%$ of the total energy used in the United States is consumed by transportation systems, and $60 \%$ of the transportation energy or $16 \%$ of the total energy consumed in the United States is used to overcome aerodynamic drag in transportation systems. Application of existing pressure drag reduction technologies to ground vehicles will provide yearly energy savings of 20 billion dollars.

\section{REFERENCES}

1. U.S. Department of Energy, http://www.doe.gov , Dec. 2002.

2. U.S. Department of Energy, Energy Information Administration, http://www.eia.doe.gov/oiaf/aeo , Dec. 2002.

3. U.S. Department of Energy, Oak Ridge National Laboratory, http://www.ornl.gov , Dec. 2002.

4. Kucheman, D.: The Aerodynamic Design of Aircraft. Pergamon Press, 1978.

5. Hucho, W. H., Editor: Aerodynamics of Road vehicles. From Fluid Mechanics to Vehicle Engineering. Butterworth-Heinemann, London, 1990.

6. U.S. Department of Energy, Lawrence Livermore Laboratory, http://eetd.lbl.gov/EA.html , Dec. 2002.

7. U.S. Department of Energy, Office of Transportation Technologies, Oak Ridge National Laboratory. Transportation Energy Data Book: Edition 22.

8. U.S. Department of Energy, Office of Energy Efficiency and Renewable Energy, Office of Industrial Technologies. http://www.oit.doe.gov/bestpractices/, Dec 2002.

9. U.S. Department of Energy, Energy Information Administration. Annual Energy Outlook. 2001. http://www.eia.doe.gov/emeu/aer/contents.html , Dec. 2002.
10. U.S. Department of Transportation, Bureau of Transportation Statistics, Transportation Statistics Annual Report 2000, BTS 01-02. http://www.bts.gov/, Dec. 2002.

11. U.S. Department of Transportation, Federal Aviation Administration, http://www2.faa.gov/, Dec. 2002.

12. Wood, R. M. and Bauer, S. X. S: The Natural Flow Wing-Design Concept. NASA TP-3139, May 1992.

13. Wood, R. M. and Bauer, S. X. S.: Flying Wings/Flying Fuselages: AIAA 2001-0311.

14. Gad-el-Hak, M.: Modern Developments in Flow Control. Appl. Mech. Rev. 49, 365, 1996.

15. Hoerner, S. F.: Fluid Dynamic Drag Hoerner, Midland Park, and N.J.. 1965.

16. Hefner, J. N., Weinstein, L. M., and Bushnell, D. M.: in Viscous Flow Drag Reduction. Progress in Astronautics and Aeronautics. Edited by G. R. Hough. AIAA, New York, 1980.

17. Lachmann, G. V.: Boundary Layer and Flow Control. Vol. 2, Pergamon Press, 1961.

18. Nakamura, S., Hively, E. M., and Conlisk, A. T.: LES Simulation of Aerodynamic Drag for Heavy Duty Trailer Trucks. FEDSM 2002-31427. Proc. Of the ASME Fluids Engr. Div. Summer Meeting, July 14-18, 2002.

19. McCallen, R., Couch, R., Hsu, J., Browand, F., Hammache, M., Loenard, A., Brady, M., Salari, K., Rutledtge, W., Ross, J., Storms, B., Heineck, J. T., Driver, D., Bell, J., and Zilliac, G.: Progress in Reducing Aerodynamic Drag for Higher Efficiency of Heavy Duty Trucks (Class 7-8). SAE 1999-01-2238, 1999

20. Angler, R. J.: Advanced Aerodynamic Devices to Improve the Performance, economics, Handling and Safety of Heavy Vehicles. SAE 2001-012072. SAE Government/Industry Meeting, May 14-16, 2001

21. Clark III, H. and Deutusch, S.: Microbubble Skin Friction Reduction on an Axisymmetric Body Under the Influence of Applied Axial Pressure Gradients. Physcis of Fluids, 3, 12, Dec. 1991, pp. 2948-2954.

22. Virk, P. S.: Drag Reduction in Rough Pipes. J. Fluid Mech. 45. 225, 1970. 
23. Lee, C., Kim, J. and Choi, H.: Suboptimal Control of Turbulent Channel Flow for Drag Reduction. J. Fluid Mech. Vol. 358, pp. 245-258, 1998.

24. Christodoulou, C., Liu, K. N., and Joseph, D. D.: Combined Effects of Riblets and Polymers on Drag Reduction in Pipes. American Int. of Physics, 3, 5, May 1991, pp. 995-996.

25. Watanabe, $\mathrm{K}$ and Udagawa, $\mathrm{H}$.: Drag Reduction of Newtonian Fluid in a Circular Pipe with a Highly Water-Repellent Wall. J. Fluid Mech. Vol. 381, pp. 225-238, 1999.

26. Choi, K and Graham, M.: Drag Reduction of Turbulent Pipe Flows by Circular-Wall Oscillation. Ltr. American Institute of physics, Vol. 10, No. 1, pp. 7-9, 1998.

27. Barlow, J. B., Guterres, R., And Ranzenbach, R.: Rectangular Bodies with Radiused Edges in Ground Effect. AIAA 99-3153.

28. American Institute of chemical Engineers, http://www.AICHE.org/, Dec. 2002.

29. Worrell, E., Phylipsen, D., Einstein, D., and Martin, N.: Energy Use and Energy Intensity of the U.S. Chemical Industry. LBNL-44314, April 2000.

30. Martin, N., Worrell, E., Ruth, M. and Price, L. : Emerging Energy-Efficient Industrial Technologies.. LBNL-46990, October 2000.

31. Martin, N., Anglani, N., Einstein, D., Khrushch, M., Worrell, E., and Price, L. K. : Opportunities to Improve Energy Efficiency and Reduce Greenhouse Gas Emissions in the U.S. Pulp and Paper Industry.. LBNL-46141, July 2000.

32. Sathaye, J., Price, L., Worrell, E., Ruth, M., Schaeffer, R., Costa, M. M., Wang, Y., Roy, J., Das, S., Winkler, H., Spalding-Fecher, R., Afrane-Okese, Y., Davidson, Q.: Multi-Project Baselines For Evaluation Of Industrial EnergyEfficiency And Electric Power Projects. LBNL48242. 2001

33. American Petroleum Institute, http://apiec.api.org/frontpage.cfm , Dec. 2002.

34. Levine, M. D.:, Martin, N., Price, and Worrell, E.: Energy Efficiency Improvement Utilizing High Technology: An Assessment of Energy Use in Industry and Buildings.. London: World Energy Council, 1995.
35. Emmerich, S. J. and Persily, A.K.: Energy Impact of Filtration and Ventilation in U. S. Office Buildings Using Multi-Zone Airflow Simulation. Proceedings of IAQ and Energy 98 Conference. New Orleans, LA 22-27 Oct. 1998. IAQ and Energy 98, pg 191-203.

36. Grot, R. A. and Persily, A. K.: Measured Air Filtration and Ventilation Rates in Eight Large Office Buildings. Proceedings of Measured Air Leakage of Buildings. ASTM STP 904, American Society for Testing and Materials.

37. VanBronkhorst, D. A., Persily, A. K., and Emmerich, S. J.: 1995. Energy Impacts of Air Leakage in U. S. Office Buildings. Proc. of $16^{\text {th }}$ AIVC Conference.

38. Kramer, B. R., Smith, B. C., Heid, J. P., Noffz, G. K., Richwine, D. M., and Ng, T.: Drag Reduction Experiments Using Boundary Layer Heating. AIAA-99-0134. 1999

39. Hwang, D. P. and Biesiadny, T. J.: Experimental Evaluation of Penalty Associated with MicroBlowing for Reducing Skin Friction. AIAA-980677. 1998

40. Corke, T. C., Jumper, E. J., Post, M. L., Orlov, D., and McLaughlin, T. E.: Application of Weakly lonized Plasmas as Wing Flow-Control Devices. AIAA 2002-0350. 2002

41. Lekoudis, S. G. and Sengupta, T. K.: TwoDimensional Turbulent Boundary Layers Over Rigid and Moving Swept Wavy Surfaces. Physics Fluids, No.. 29, Vol. 4, April 1986, pp. 964-970.

42. Sahlin, A., Alfredsson, P. H., Johansson, A. V.: Direct Drag Measurements for a Flat Plate with Passive Boundary Layer Manipulators. Physics Fluids, No.. 29, Vol. 3, April 1986, pp. 696-700.

43. Schlichting, H.: Boundary Layer Theory. McGraw Hill, New York, NY, 1977.

44. Cadot, O., Bonn, D., and Douady, S.: Turbulent Drag Reduction in a Closed Flow System: Boundary layer Versus Bulk Effects. Physics of Fluids. Vol 10, No. 2, Feb 1998 pp. 426-436.

45. Kang, S. and Choi, H.: Active Wall Motions for Skin Friction Drag Reductions. Physics of Fluids. Vol. 12, No. 12, Dec. 2000, pp. 3301-3304.

46. Lee, C and Kim, J.: Control of the Viscous Sublayer for Drag Reduction. Physics of Fluids, Vol. 14, No. 7, July 2002, pp. 2523-2529. 
47. Baron, A. and Quadrio, M.: Turbulent Boundary Layer Over Riblets: Conditional Analysis of Ejection-Like Events. Int. J. Heat and Fluid Flow, Vol. 18, No. 2,pp.:188-196, 1997.

48. Endo, T., Kasagi, N. and Suzuki, Y.: Feedback Control of Wall Turbulence with Wall

Deformation. Int. J. of Heat and Fluid Flow, 21, pp. 568-575, 2000.

49. Choi, K and Clayton, B. R.: The Mechanism of Turbulent Drag Reduction with Wall Oscillation. Int. J. of Heat and Fluid Flow, 22, pp. 1-9, 2001.

50. Satake, S. and Kasagi, N.: Turbulence Control with Wall-Adjacent Thin Layer Damping Spanwise Velocity Fluctuations. Int. J. of Heat and Fluid Flow, Vol. 17, No. 3, June 1996, pp. 343-352.

51. Nouri, J. M. and Whitelaw, J. H.: Flow of Newtonian and non-Newtonian Fluids in an Eccentric Annulus with Rotation on the Inner Cylinder. Int. J. of Heat and Fluid Flow, Vol. 18, No. 2, April 1997, pp. 236-246.

52. Kerho, M.: Active Reduction of Skin Friction Drag Using Low-Speed Streak Control (Invited). AIAA 2002-0271, Jan. 14-17 2002.

53. Choi, K. -S., Yang, X., Clayton, B. R., Glover, E. J., Atlar, M., Semenov, B. N., and Kulik, V. M.: Turbulent Drag Reduction Using Compliant Surfaces. Proc. R. Soc. London A, 453, pp. 2229-2240, 1997.

54. Skvortsov, V., Kuznetsov, Y., Klimov, A., Leonov, S., Markin, V. and Uspenskii, A.: Investigation of the Plasma Aerodynamic Effects on the Models of Various Geometry. AIAA 994854, 1999..

55. Schubauer, G. B. and Spangenberg, W. G.: Forced Mixing in Boundary layers. NBS Rpt. 6107, Aug. 1958.

56. McComb, W. D. and Rabie, L. H.: Local Drag Reduction Due to Injection of Polymer Solutions into Turbulent Flow in a Pipe. AIChE J., 28, 547, 1982.

57. Kawaguchi, Y., Segawa, T., Feng, Z. and Li, P.: Experimental Study on Drag-Reducing Channel Flow with Surfactant Additives-Spatial Structure of Turbulence Investigated by PIV System. Int. J. of Heat and Fluid Flow, 23, pp. 700-709, 2002.
58. Den Toonder, J. M. J., Hulsen, M. A., Kuiken, G. D. C., and Nieuwstadt, F. T. M.: Drag Reduction by Polymer Additives in a Turbulent pipe Flow: Numerical and Laboratory Experiments. J. Fluid Mech. Vol. 337, pp. 193-231, 1997.

59. Sreenivasan, K. R. and White, C. M.: The Onset of Drag Reduction by Dilute Polymer Additives, and the Maximum Drag Reduction Asymptote. J. Fluid Mech. Vol. 409, pp. 149-164, 2000.

60. Koskie, J. E. and Tiederman, W. G.: Polymer Drag Reduction of a Zero-Pressure Gradient Boundary Layer. Phys. Fluids, Vol. 3, No. 10, pp. 2471-2473, 1991.

61. Ashill, P. R., Fulker, J. L. and Hackett, K. C.: Studies of Flows Induced by Sub Boundary Layer Vortex Generators (SBVGs). AIAA-200214121.

62. Walsh, M. J.: Riblets as a Viscous Drag Reduction Technique. AIAA Journal, Vol. 21, No. 4, Apr. 1983, pp. 485-486.

63. Bons, J. P., Sondergaard, R. and Rivir, R. B.: Turbine Separation Control Using Pulsed Vortex Generator Jets. ASME paper 2000-GT-0262.

64. Neiuwstadt, F. T. M., Wolthers, W., Leijdens, H., Krishna Prasad, K. and Schwarz-van Manen, A.: The Reduction of Skin Friction by Riblets Under the Influence of an Adverse Pressure Gradient. Exp. In Fluids, Vol. 15, pp. 17-26, 1993.

65. Lynch, F. T. and Klinge, M. D.: Some Practical Aspects of Viscous Drag Reduction Concepts. SAE Paper 912129, Sept 1991.

66. Hefner, J. N. and Bushnell, D. M.: Viscous Drag Reduction Via Surface Mass Injection. In Viscous Drag Reduction in Boundary layers, AIAA, 1989.

67. Hwang, D. P.: A Proof of Concept Experiment for Reducing Skin Friction by Using a MicroBlowing Technique. AIAA 97-0546.

68. Seifert, A., Bachat, T., Koss, D., Shepshelovich, M. and Wygnanski, I.: Oscillatory Blowing: A Tool to Delay Boundary-layer Separation. AIAA Journal, Vol. 31, No. 11, Nov. 1993, pp. 20522060.

69. Mode, V. J. and Deshpande, V. S.: Aerodynamics of a Building with Momentum Injection. AIAA 2001-2456. 
70. Bur, R., Corbel, B. and Delery, J.: Study of Passive Control in a Transonic Shock Wave/Boundary Layer Interaction. AIAA 970217.

71. Bramesfeld, G. and Maughmer, M. D.: Experimental Investigation of Self-Actuating, Upper Surface, High-Lift-Enhancing Effectors. J. of Aircraft, Vol. 39, No. 1, Jan-Feb 2002, pp. 120-124.

72. Rao, N. M., Feng, J., Burdisso, R. A., and Ng, W. F.: Active Flow Control to Reduce Fan Blade Vibration and Noise. AIAA 99-1806.

73. Dima, C. and deMatteis, P.: Effects of Shock and Boundary-Layer Control Techniques on Transonic Flows About Airfoils. AIAA 20000517.

74. McMichael, J. M.: Progress and Prospects for Active Flow Control Using Micro-Fabricated Electro-Mechanical Systems (MEMs). AIAA 960306.

75. de Jager, B: Rotating Stall and Surge Control: A Survey. Prec., $34^{\text {th }}$ IEEE Confg. On Decision and Control, New Orleans, LA, 1995, pp. 18571862.

76. Kerrebrock, J. L., Zdrela, M., Merchant, A. A., and Schuler, B. J.: A Family of Designs for Aspirated Compressors. ASME 98-GT-196, 1998.

77. Zaman, K. B. M. Q.: Effects of Delta Tabs on Mixing and Axis Switching in Jets from Axisymmetric Nozzles. AIAA 94-0186.

78. Wood, N. and Nielsen, J.: Circulation Control Airfoils Past, Present, Future. AIAA 85-0204

79. Nielsen, J. N. and Biggers, J. C.: Recent Progress in Circulation Control Aerodynamics. AIAA 87-0001.

80. Qin, N., Zhu, Y., Ashill, P. and Shaw, S. T.: Active Control of Transonic Aerodynamics Using Suction, Blowing, Bumps and Synthetic jets. AIAA 2000-4329.

81. Gilarranz, J. L. and Rediniotis, O. K.: Compact, High-Power Synthetic Jet Actuators for Flow Separation Control. AIAA 2001-0737.

82. McCormick, D. C.: Boundary Layer Separation Control with Directed Synthetic Jets. AIAA 000519 .
83. Tillman, T. G. and Hwang, D. P.: Drag Reduction on a Large Scale Nacelle Using a Micro-Blowing Technique. AIAA 99-0130.

84. Lord, W. K., MacMartin, D. G., and Tillman, T. G.: Flow Control Opportunities in Gas Turbine Engines. AIAA 2000-2234.

85. Miller, D. N., Yagle, P. J., and Hamstra, J. W.: Fluidic Throat Skewing for Thrust Vectoring Nozzles in Fixed Geometry Nozzles. AIAA 990365 .

86. Decker, R. K., Naughton, J. W. and Whitmore, S. A.: Modification of Base Drag Through Boundary-Layer Manipulation. AIAA 20020273. Jan 14-17, 2002.

87. Viswanath, P. R.: Drag Reduction of Afterbodies by Controlled Separated Flows: Generic Study. AIAA 99-0274.

88. Whitmore, S. A., Sprague, S. and Naughton, J. W.: Wind-Tunnel Investigations of Blunt-Body Drag Reduction Using Forebody Surface Roughness. AIAA 2001-0252.

89. Rathakrishnan, E.: Effect of Splitter Plate on Bluff Body Drag. AIAA Journal, Vol. 37, No. 9, Sept, 1999, pp. 1125-1126.

90. Grosche, F. R. and Meier, G. E. A.: Research at DLR Gottingen on Bluff Body Aerodynamics, Drag Reduction by Wake Ventilation and Active Flow Control. J. of Wind Engr. And Ind. Aero. Vol. 89, pp. 1201-1218, 2001.

91. Mair, W. A.: Reduction of Base Drag by BoatTailed Afterbodies in Low-Speed Flow. Aero. Q.., Vol. 20, pp. 307-320., 1969.

92. Deere, K. A. and Hunter, C. A.: Experimental Investigation of Convoluted Contouring for Aircraft Afterbody Drag Reduction. AIAA 992670.

93. Tanner, M.: New Investigations for Reducing the Base Drag of Wings with a Blunt Trailing Edge. Paper 12, AGARD Conference Proc. No. 124 on Aerodynamic Drag, April 1973

94. Bearman, P. W.: Investigation of the Flow Behind a Two-Dimensional Model with Blunt Trailing Edge and Fitted with Splitter Plates. J. Fluid Mechanics, Vol. 21, 1965, pp. 241-255. 
95. Bearman, P. W.: Investigation into the Effects of Base Bleed on the Flow Behind a TwoDimensional Model with a Blunt Trailing Edge. AGARD Conf. Proc. No. 4, Separated Flows, Part 2, 1966, pp. 479-507.

96. Nash, J. F.: A Discussion of Two-Dimensional Turbulent Base Flows. ARC R\&M No. 3466, 1966.

97. Raynor, P. C.: Flow Field and Drag for Elliptical Filter Fibers. Aerosol Sci. and tech., Vol. 36, pp. 1118-1127, 2002.

98. Levin, D., Daser, G. and Shpund, Z.: On the Aerodynamic Drag of Ribbons. AIAA 97-1525.

99. Sobieczky, H, Geissler, W. and Hannemann, M.: Expansion Shoulder Bump for Wing Section Viscous/Wave Drag Control. IUTAM Symp. On Mechanics of Passive and Active Flow Control, Sept 7-11, 1998.

100. Tamura, T. and Miyagi, T.: The Effect of Turbulence on Aerodynamic Forces on a Square Cylinder with Various Corner Shapes. J. of Wind Engr. and Ind. Aero., Vol. 83, pp. 135-145, 1999.

101. Bauer, S. and Wood, R.: Base Passive Porosity for Drag Reduction. United States Patent 6,286,892, Sept. 11, 2001.

102. Beechert, D. W., Bruse, M., Hage, W. and Meyer, R.: Biological Surfaces and Their Technological Application - Laboratory and Flight Experiments on Drag Reduction and Separation Control. AIAA 1997-1960, 1997.

103. Barrett, D. S., Triantafyllou, M. S., Yue, D. K. P., Grosenbaugh, M. A. and Wolfgang, M. J.: Drag Reduction in Fish-Like Locomotion. J. of Fluid Mech. Vol. 392, pp. 183-212, 1999.

104. Anders, J. B.: Biomimetric Flow Control. AIAA 2000-2543.
105. Bechert, D. W., Bruse, M., Hage, W. and Meyer, R.: Biological Surfaces and Their Application Laboratory and Flight Experiments on Drag Reduction and Separation Control. AIAA 971960.

106. Lighthill, M. J.: Hydromechanics of Aquatic Animal Propulsion. Annual Review of Fluid mech., Vol. 1, 1969, pp. 413-436.

107. Kuchemann, D.: The Aerodynamic Design of Aircraft. Pergamon Press, NY, 1978.

108. Kruppa, E. W.: A Wind Tunnel Investigation of the Kasper Vortex Concept. AIAA 77-310, Jan. 10-13, 1977.

109. Wood, R. M. and Bauer, S. X. S: Simple and Low-Cost Aerodynamic Drag Reduction Devices for Tractor -Trailer Trucks. SAE 2003-01-3377, November 2003.

110. Banks, D. W., Hall, R. M., Erickson, G. E., and Fisher, D. F.: Forebody Flow Field Effects on the High Angle-of-Attack Lateral-Directional Aerodynamics of the F/A-18. AIAA-94-0170, Jan. 10-13, 1994.

111. Low Speed Wind Tunnel Testing, $2^{\text {nd }}$ Edition. Rae, W. H. Jr. and Pope, A.. John Wiley and Sons, NY 1978.

\section{CONTACT}

Richard M. Wood

solutions@solusinc.com

www.solusinc.com 


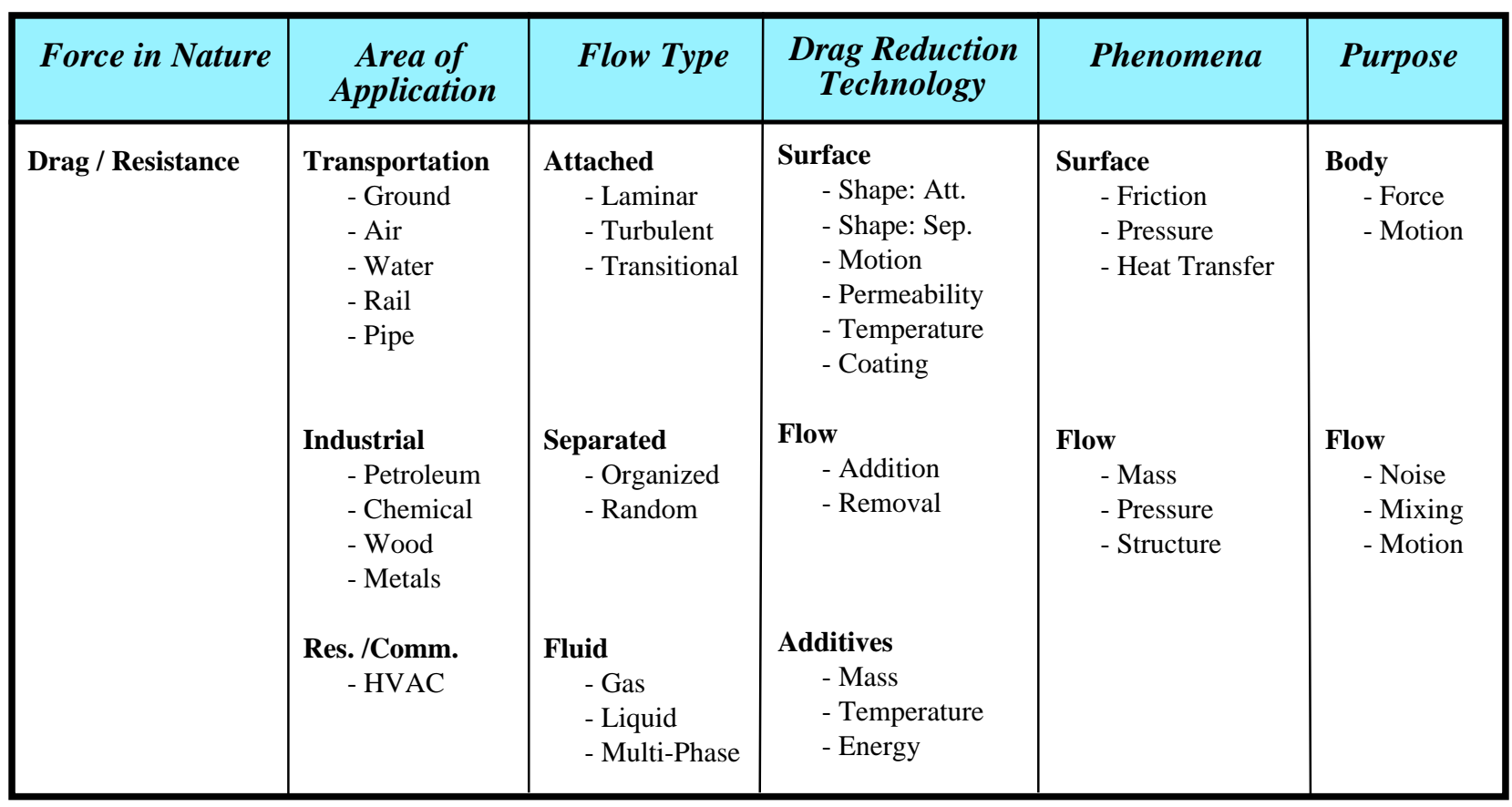

Figure 1. Interrelationship between drag force, application area, flow type, technology effectors and flow phenomena

\begin{tabular}{|c|c|c|}
\hline Transportation & Industrial & Res. / Comm. \\
\hline $\begin{array}{l}\text { Surface } \\
\text { - Shape } \\
\text { - Truck Cab Fairing } \\
\text { - Motion } \\
\text { - Rotating Cylinder } \\
\text { - Permeability } \\
\text { - Passive Porosity } \\
\text { - Temperature } \\
\text { - Laminar Flow Control } \\
\text { - Coating } \\
\text { - Polymers, Watercraft }\end{array}$ & $\begin{array}{l}\text { Surface } \\
\text { - Shape } \\
\text { - Piping and Diffusers } \\
\text { - Permeability } \\
\text { - Passive Porosity } \\
\text { - Coating } \\
\text { - Polymers, Piping }\end{array}$ & $\begin{array}{l}\text { Surface } \\
\text { - Shape } \\
\text { - Fan Diffusers } \\
\text { - Permeability } \\
\text { - Screens }\end{array}$ \\
\hline $\begin{array}{l}\text { Flow } \\
\text { - Addition } \\
\text { - Base Area Bleed } \\
\text { - Removal } \\
\text { - Airfoil Shock Control }\end{array}$ & $\begin{array}{l}\text { Flow } \\
\text { - Addition } \\
\text { - Slot Injection } \\
\text { - Removal } \\
\quad \text { - Separation Control }\end{array}$ & $\begin{array}{l}\text { Flow } \\
- \text { NA }\end{array}$ \\
\hline $\begin{array}{l}\text { Additives } \\
\text { - Mass } \\
\text { - Circulation Control } \\
\text { - Temperature } \\
\text { - Base Burning } \\
\text { - Energy } \\
\text { - Vortex Generators }\end{array}$ & $\begin{array}{l}\text { Additives } \\
\text { - Mass } \\
\text { - Polymers in Piping } \\
\text { - Temperature } \\
\text { - Base Burning } \\
\text { - Energy } \\
\text { - Vortex Generators }\end{array}$ & $\begin{array}{l}\text { Additives } \\
\text { - Energy } \\
\text { - Vortex Generators }\end{array}$ \\
\hline
\end{tabular}

Figure 2. Representative drag reduction flow control effectors. 


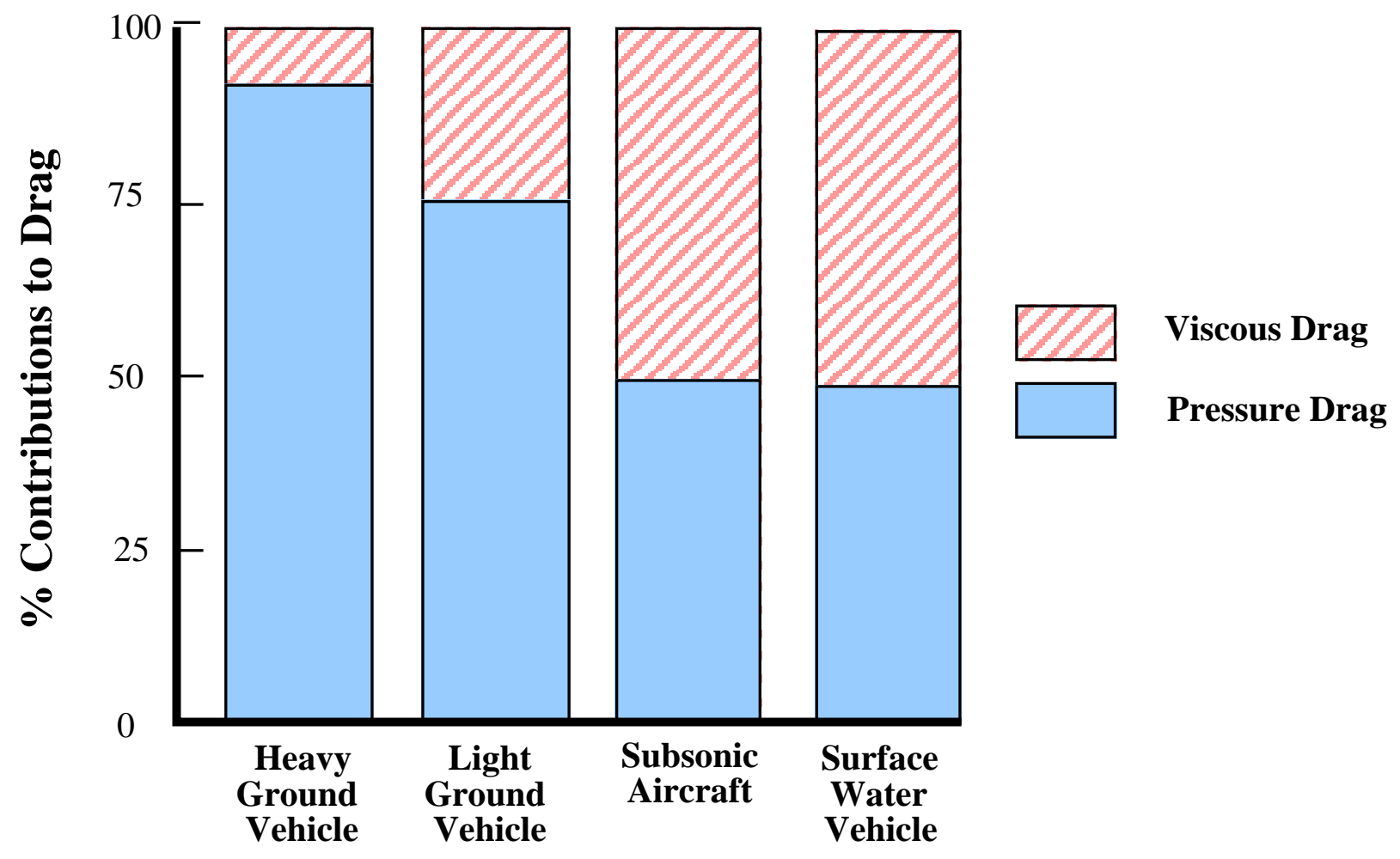

Figure 3. Distribution of drag forces for ground, air and water vehicles.

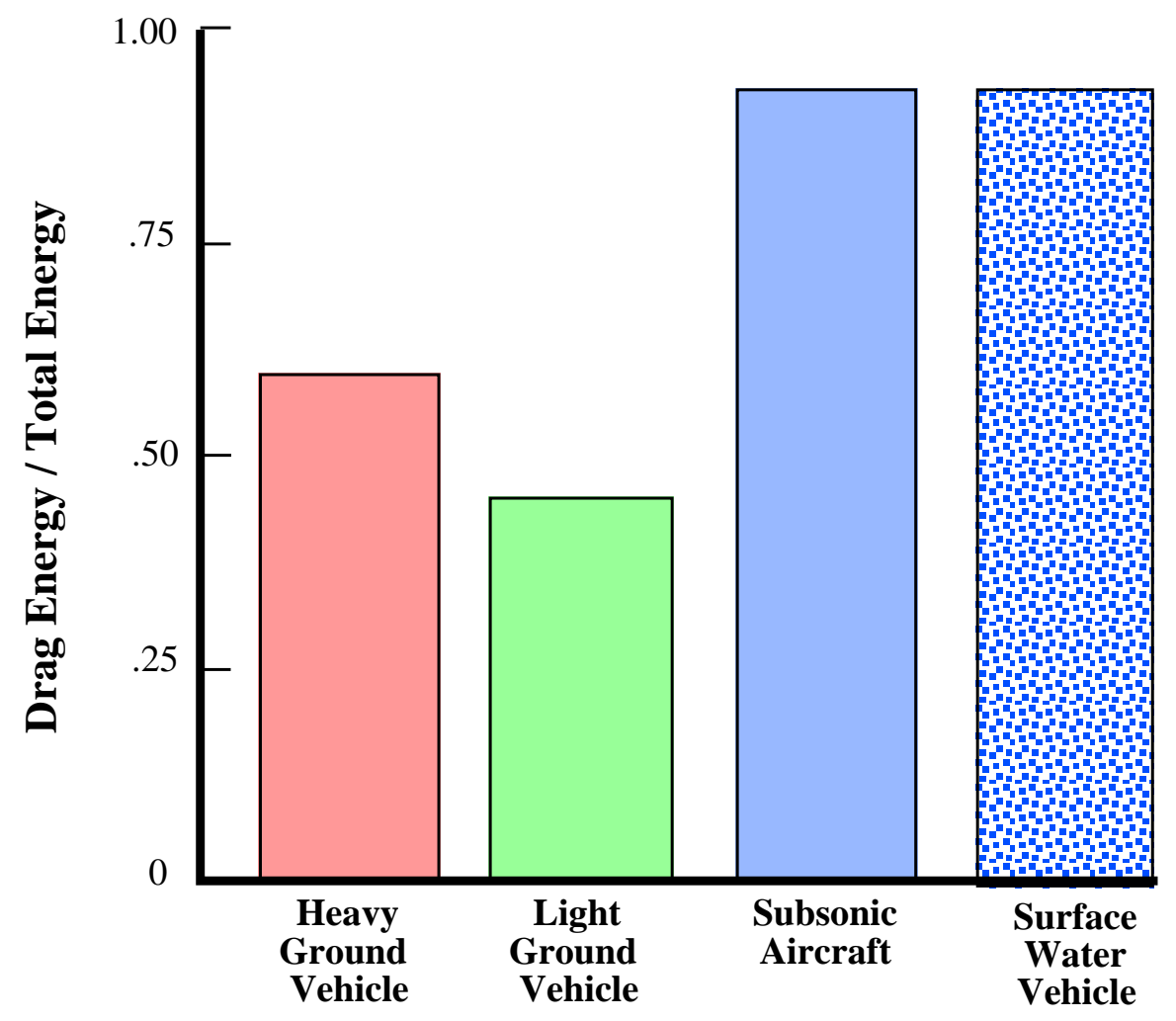

Figure 4. Energy consumed to overcome drag for ground, air, and water vehicles. 


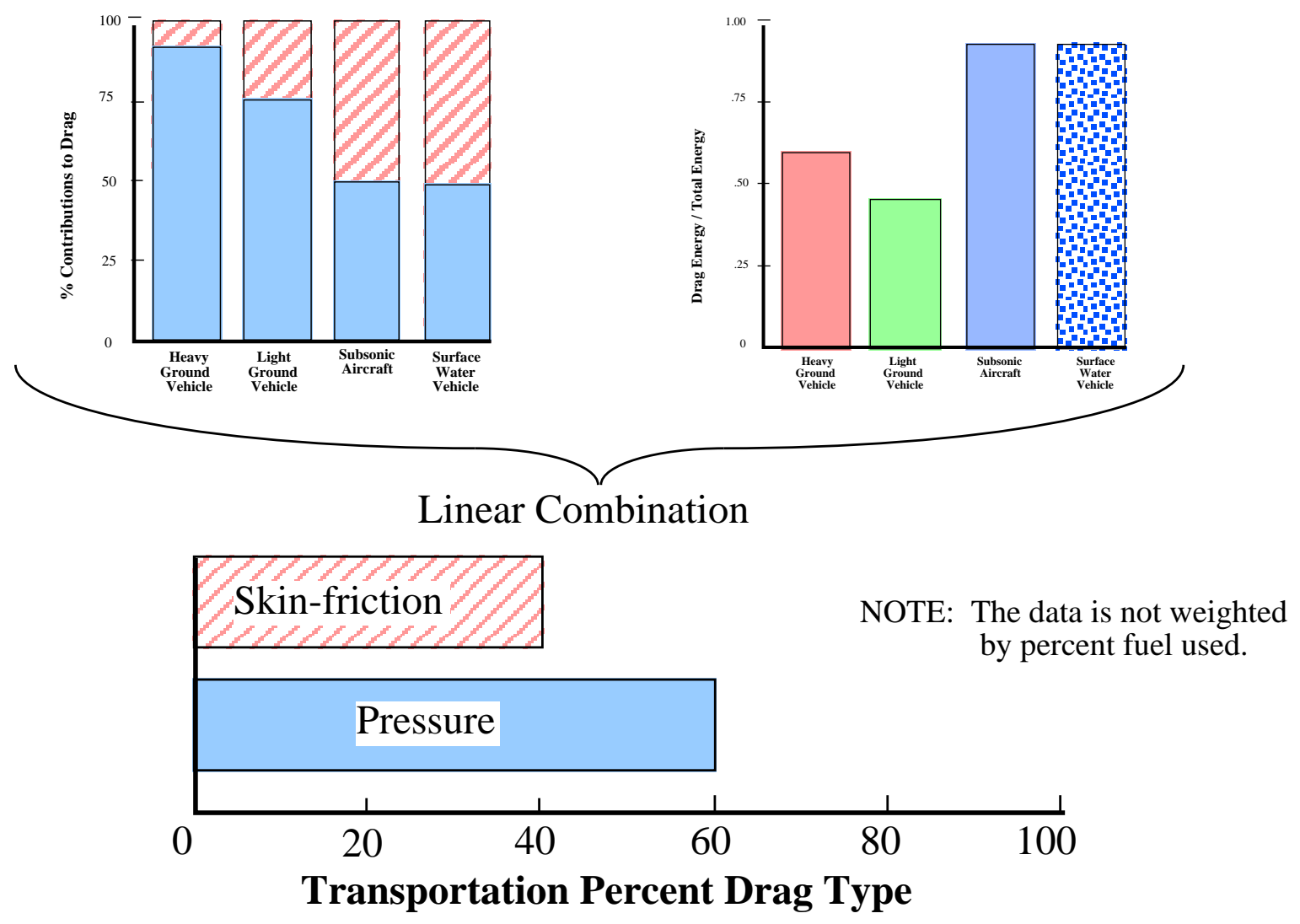

Figure 5 Distribution of drag forces for the transportation sector.

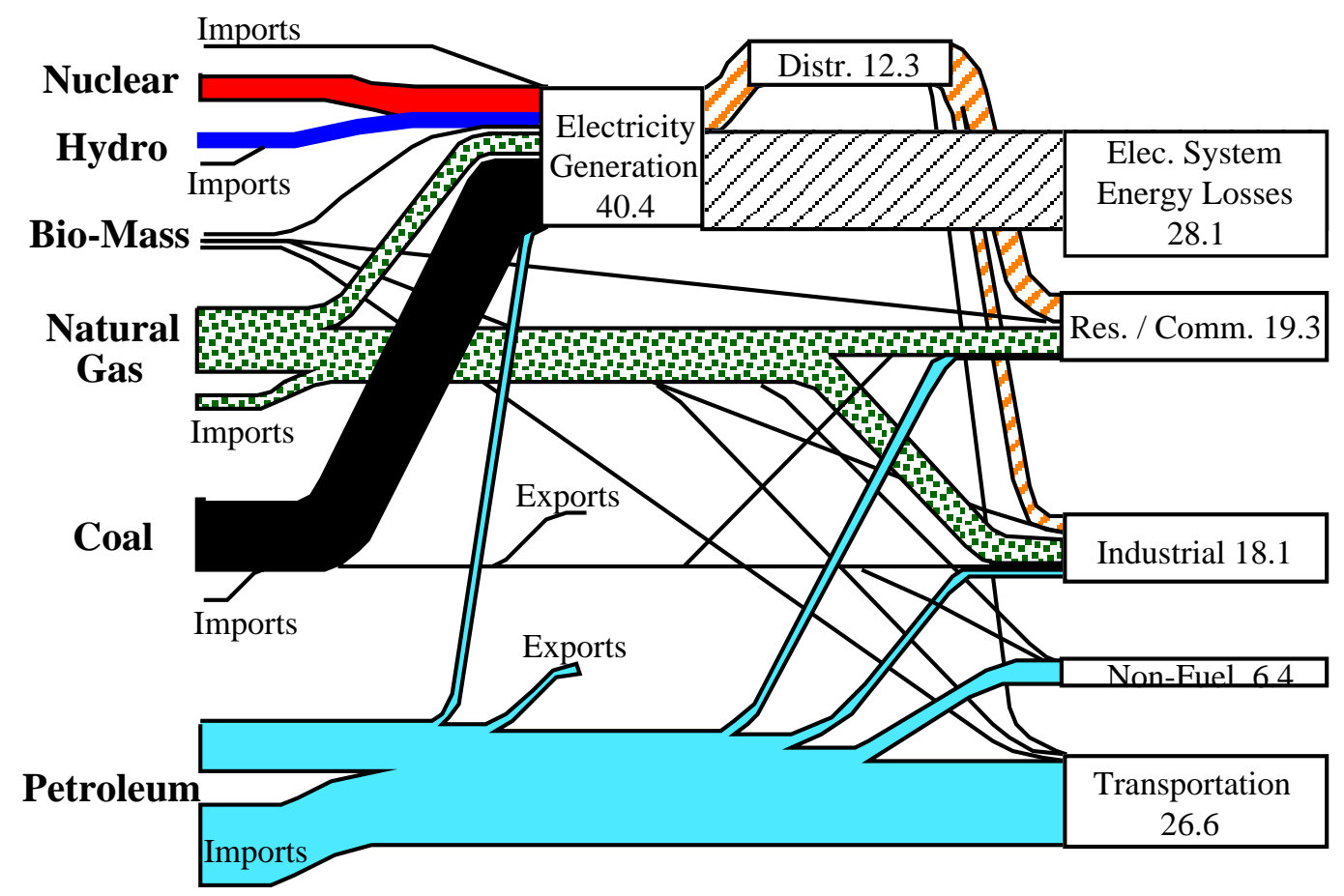

DOE, Energy Information Administration, Annual Energy Review 2000 U.S. Energy Flow Trends, Net Primary Resource Consumption 98.5 QUADS

Figure 6. Energy flow trends for the United States in 2000. 


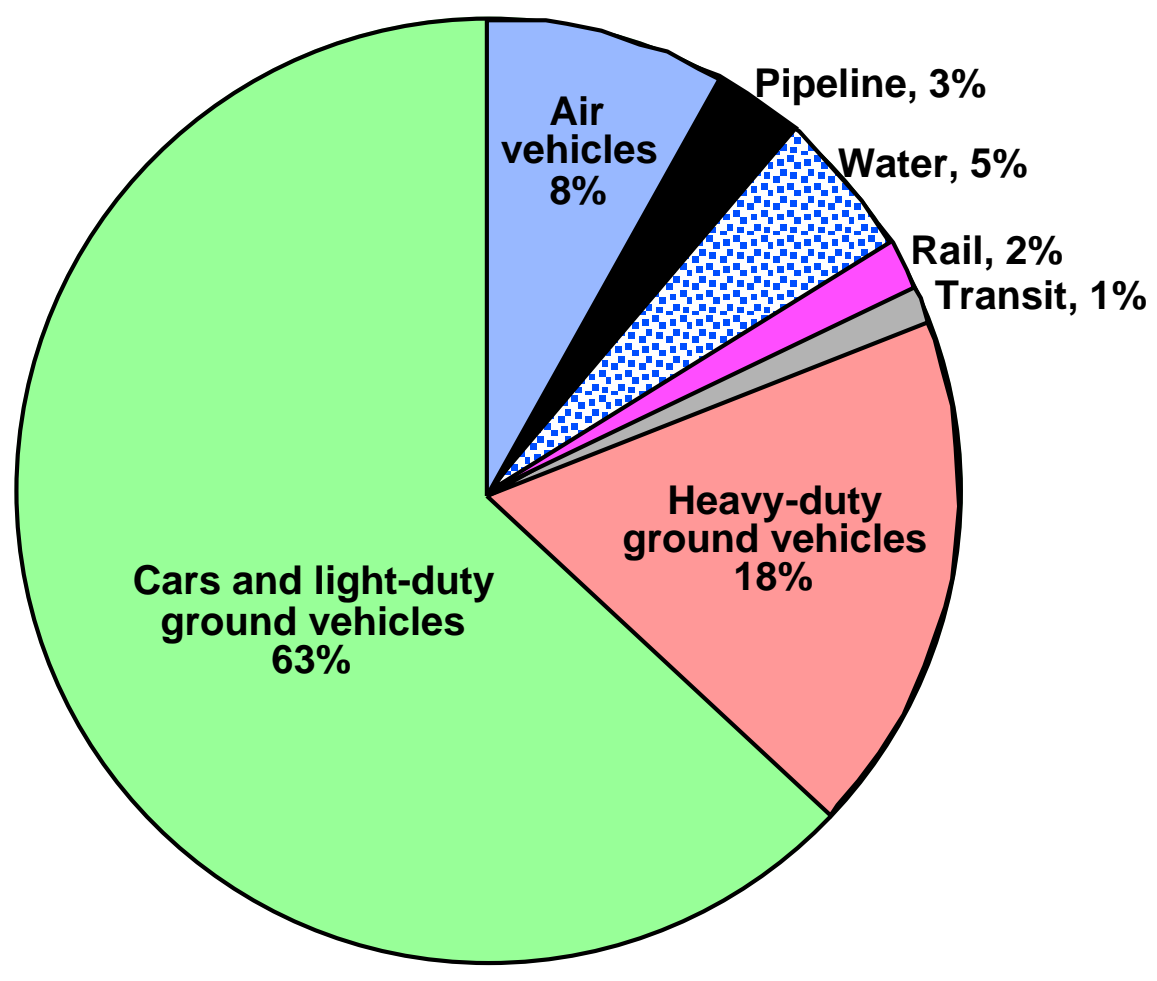

Figure 7. Distribution of transportation energy consumption.
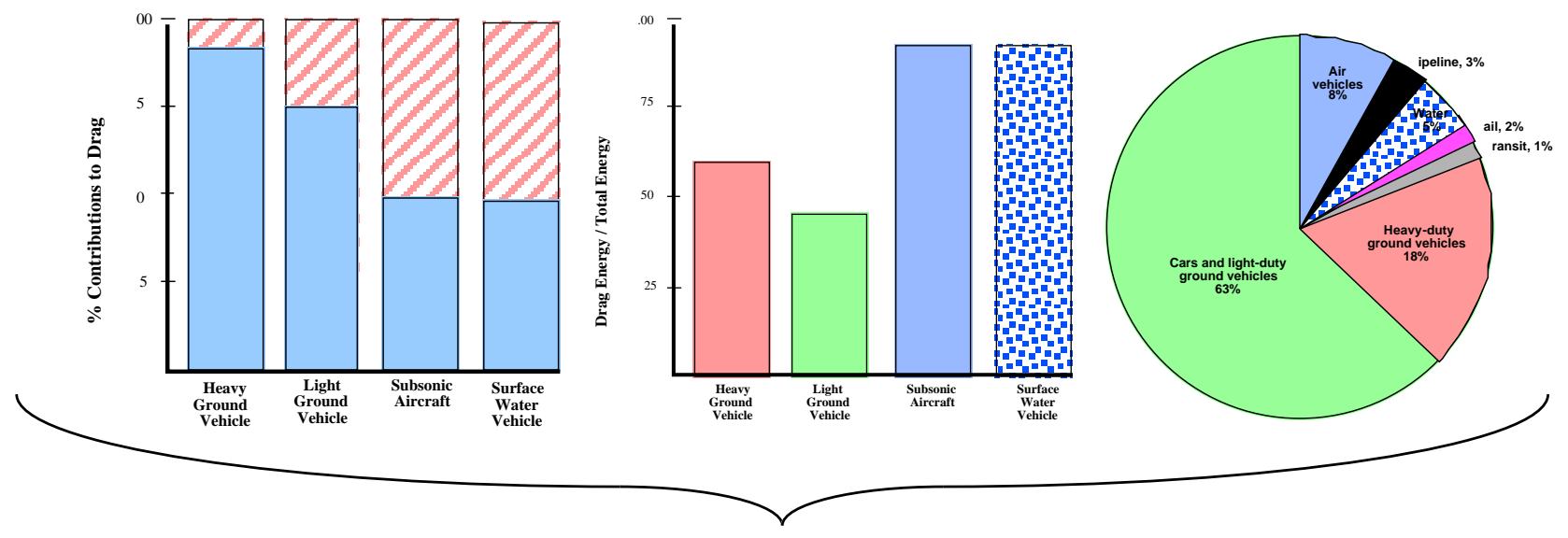

inear Combination

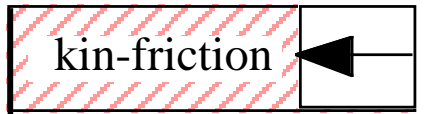

OTE: The data is weighted by percent fuel used.

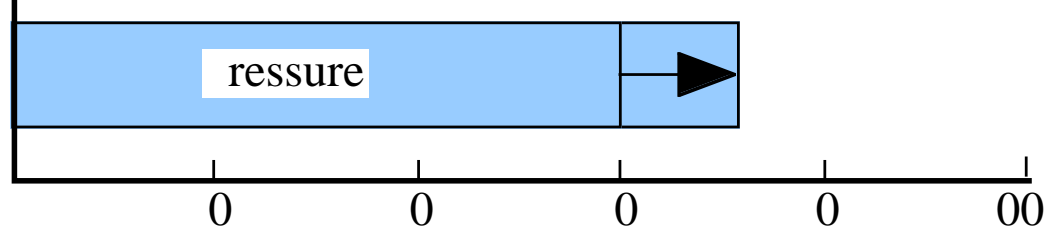

ransportation Percent Drag Type

Figure 8. Fuel usage weighted distribution of drag forces for the transportation sector. 

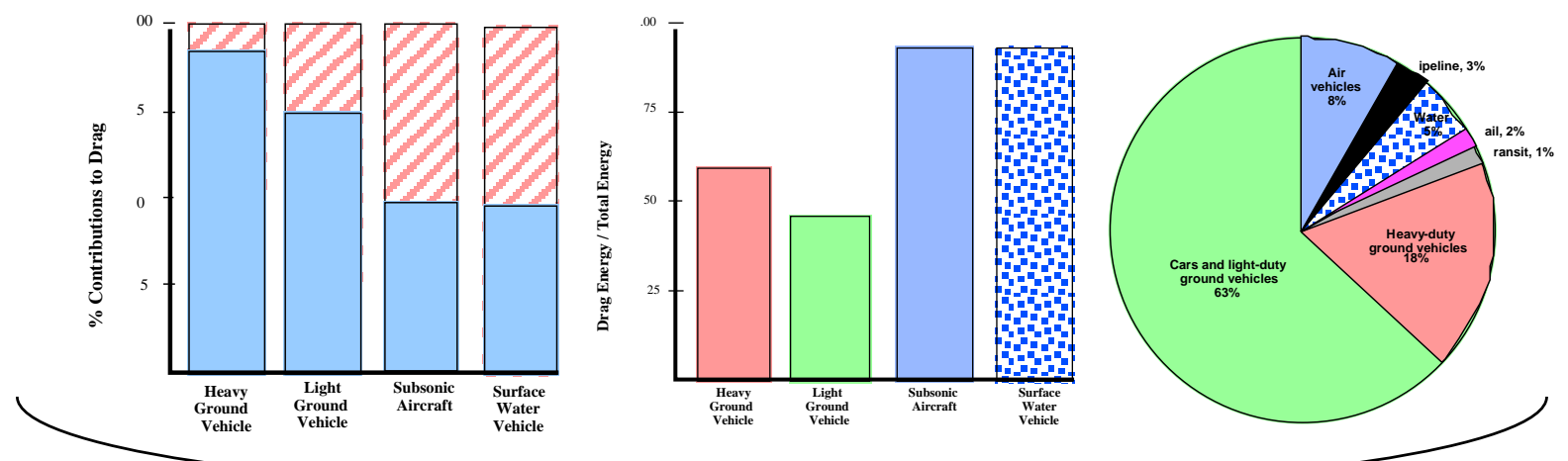

inear Combination

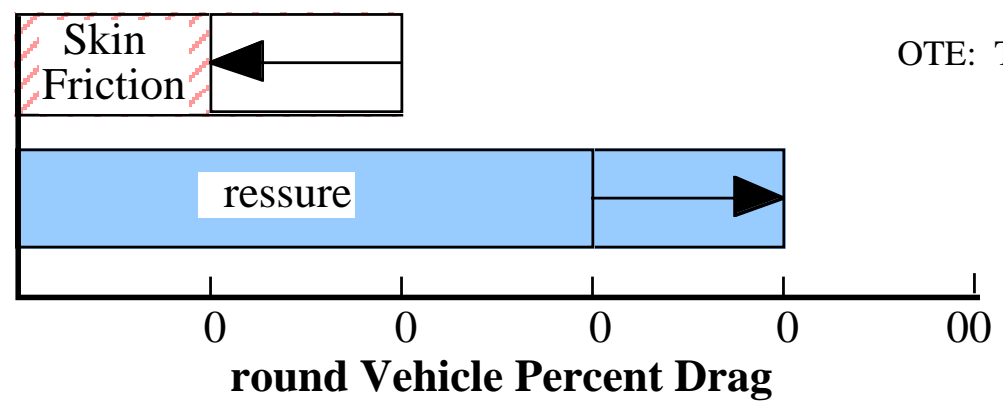

The data is weighted
by percent fuel used.

Figure 9. Fuel usage weighted distribution of drag forces for the ground transportation sector.

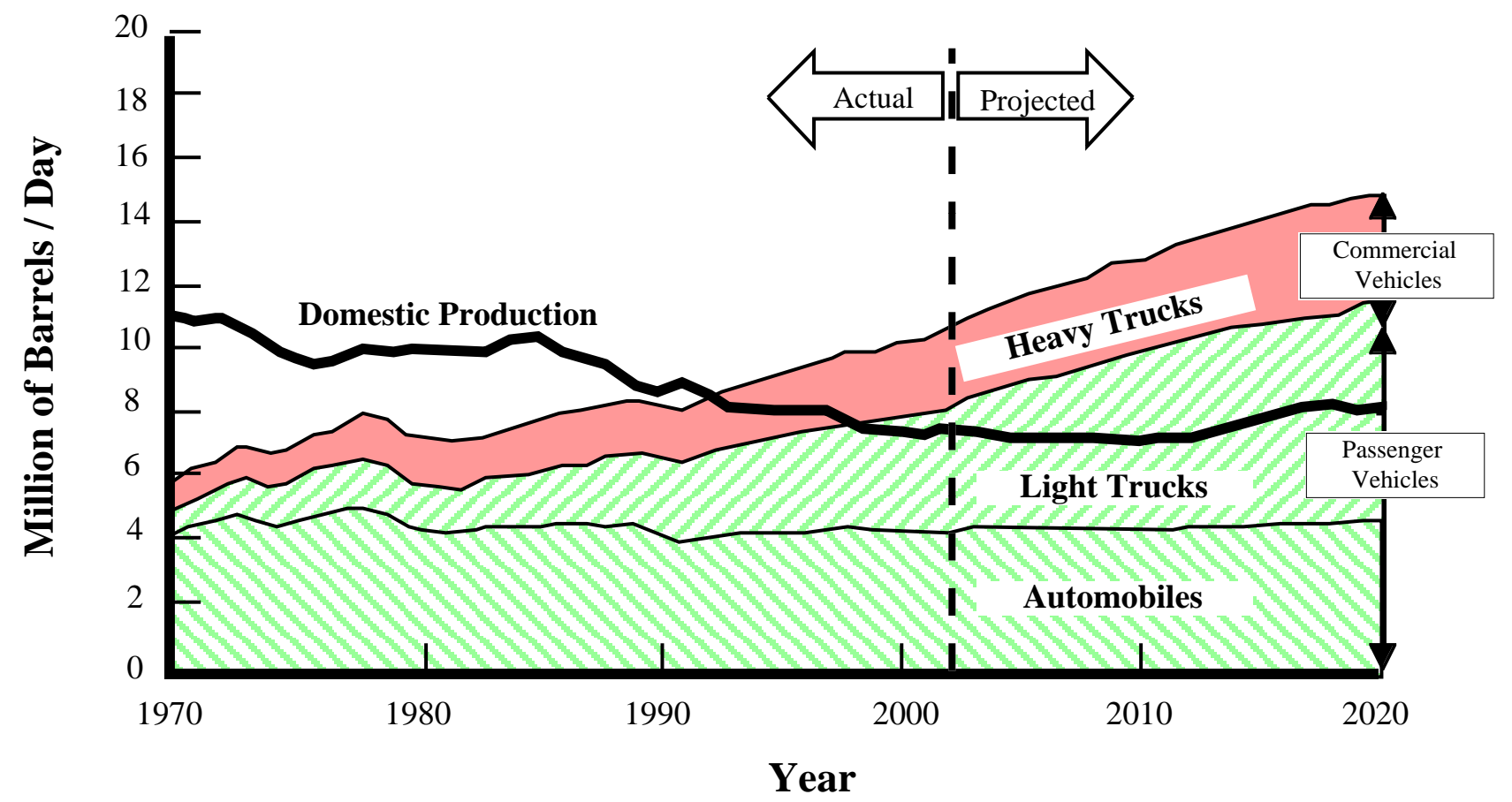

Figure 10. Historical trend in transportation energy consumption. 


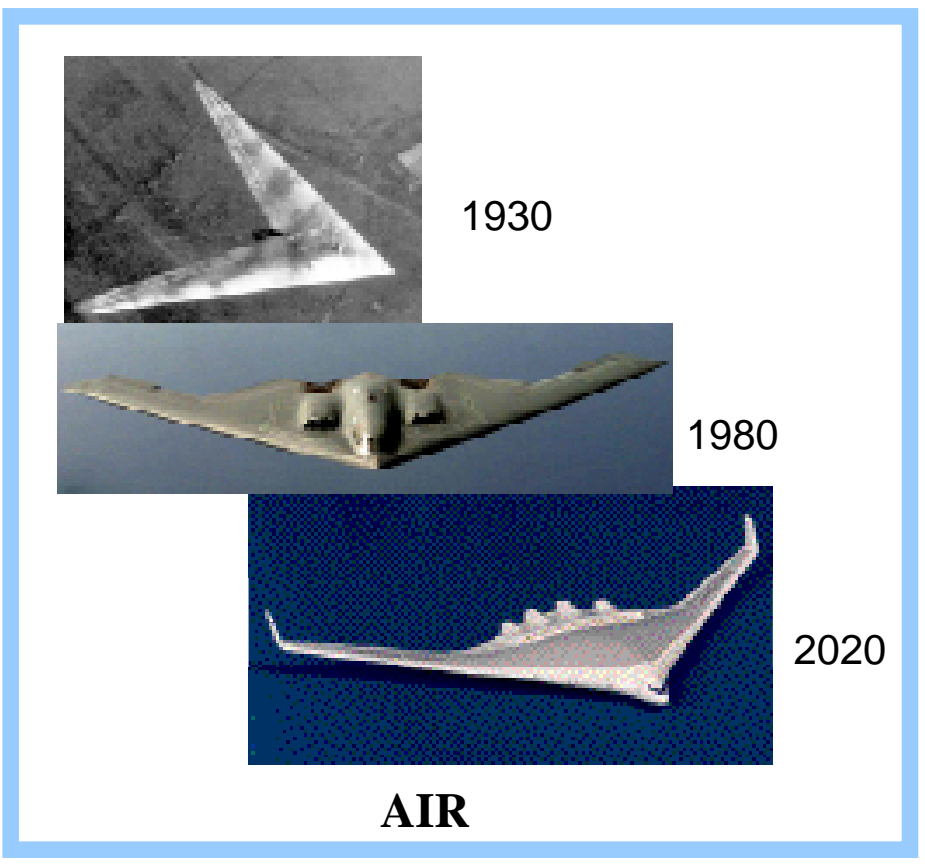

$>30 \%$ Drag Reduction

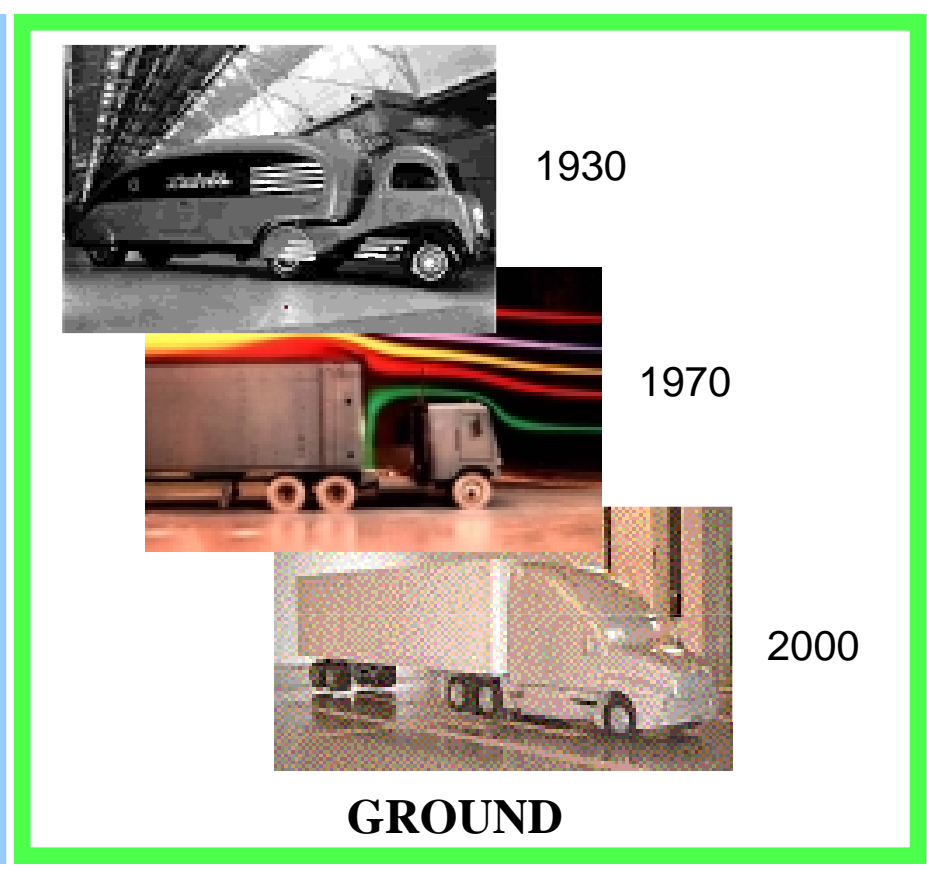

$>30 \%$ Drag Reduction

Figure 11. Attached flow surface shaping drag reduction technology.

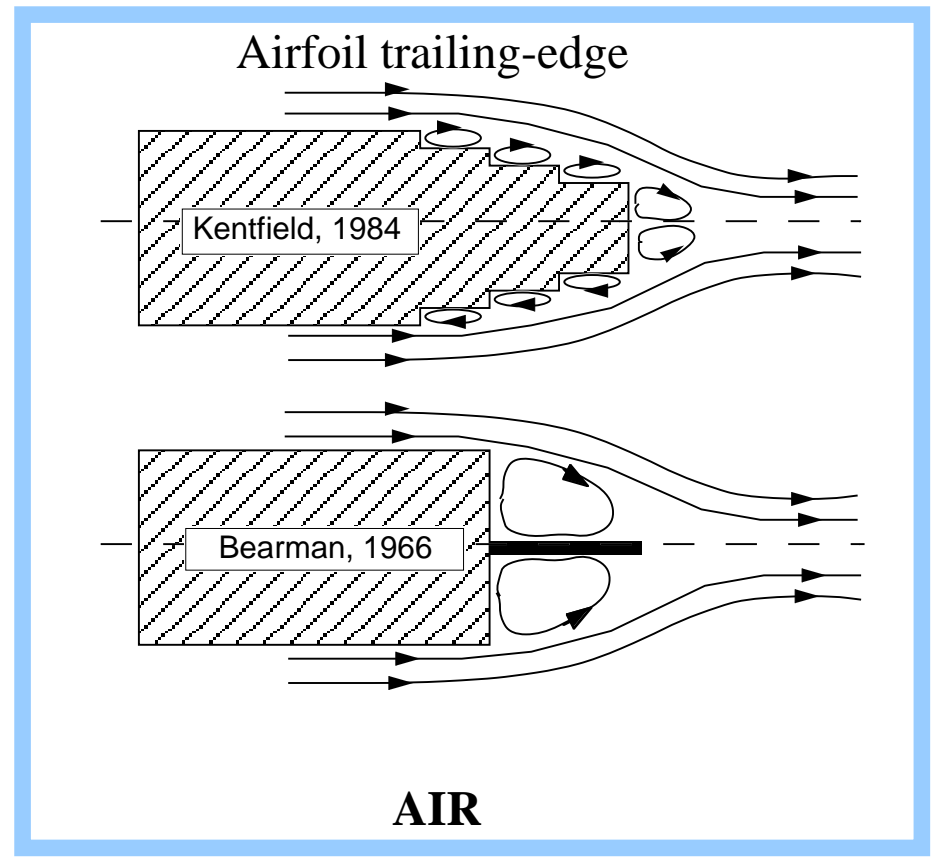

\section{$>10 \%$ Drag Reduction}

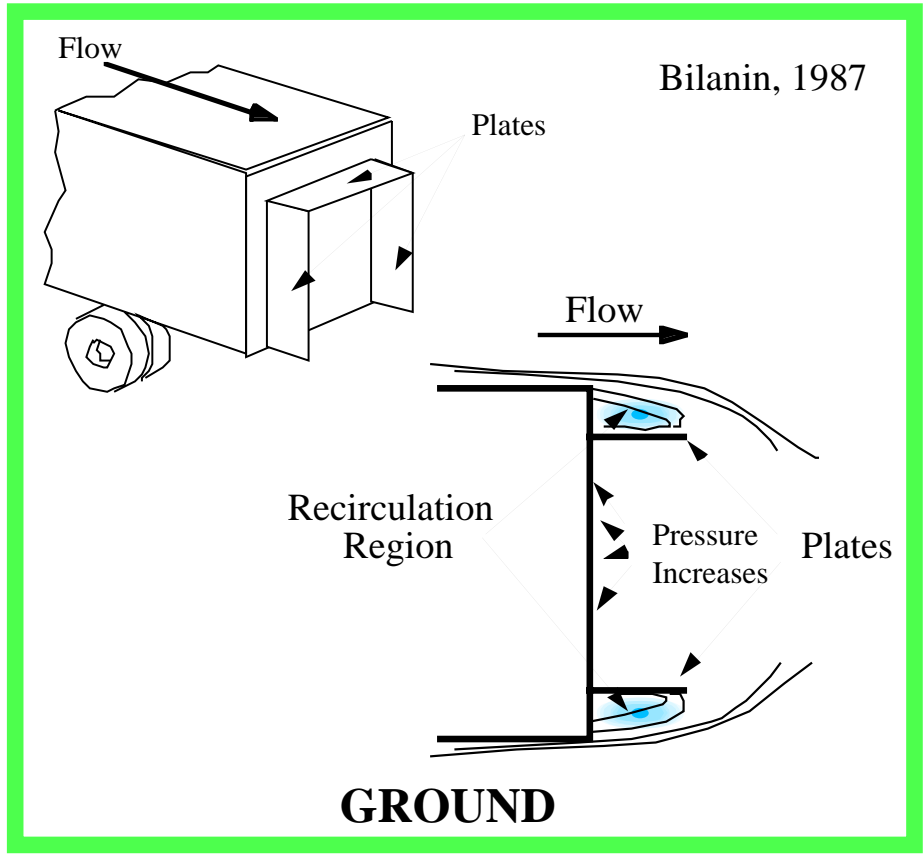

$>10 \%$ Drag Reduction

Figure 12. Bluff base separated flow surface shaping drag reduction technology. 

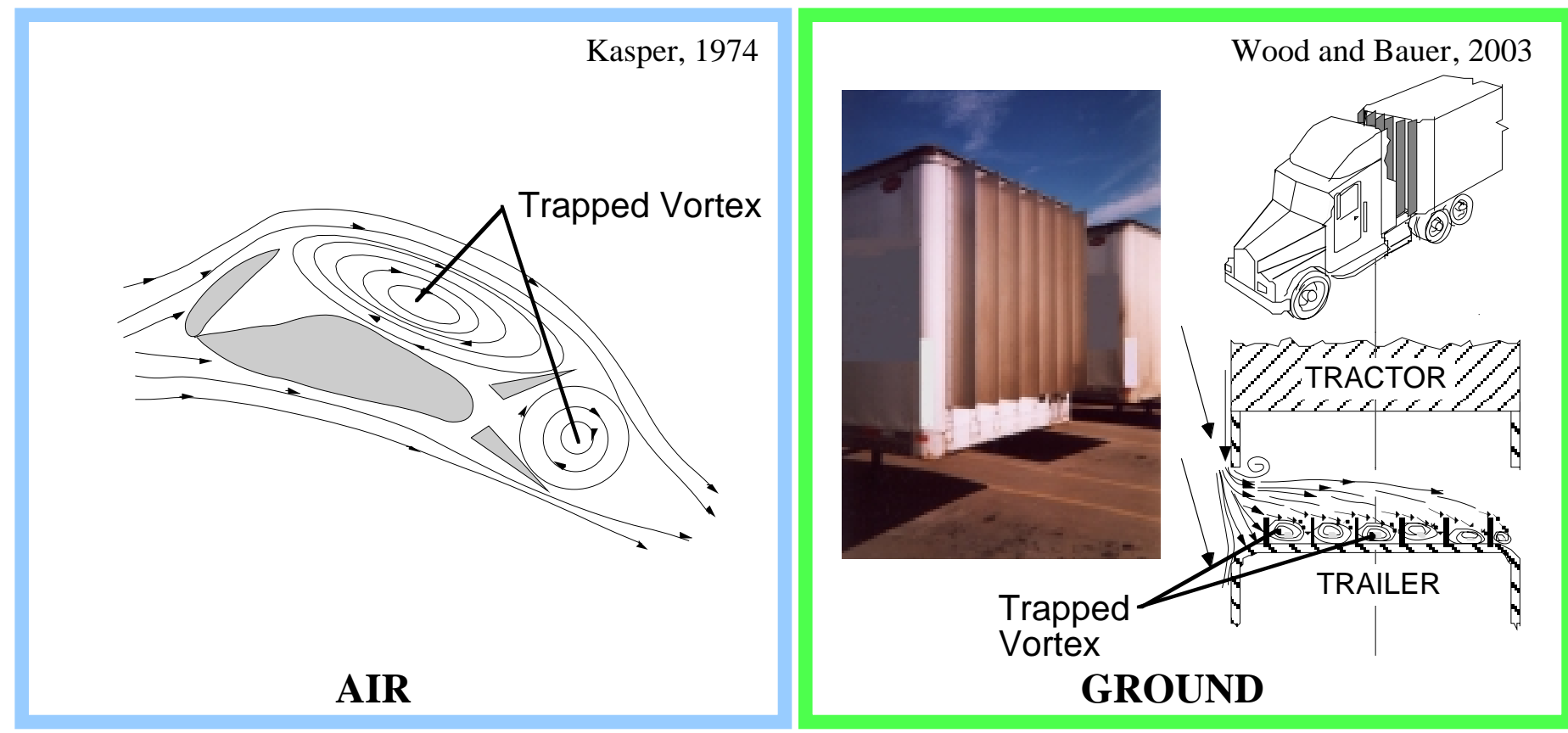

\section{$>10 \%$ Drag Reduction}

\section{$>20 \%$ Drag Reduction}

Figure 13. Trapped vortex separated flow surface shaping drag reduction technology.

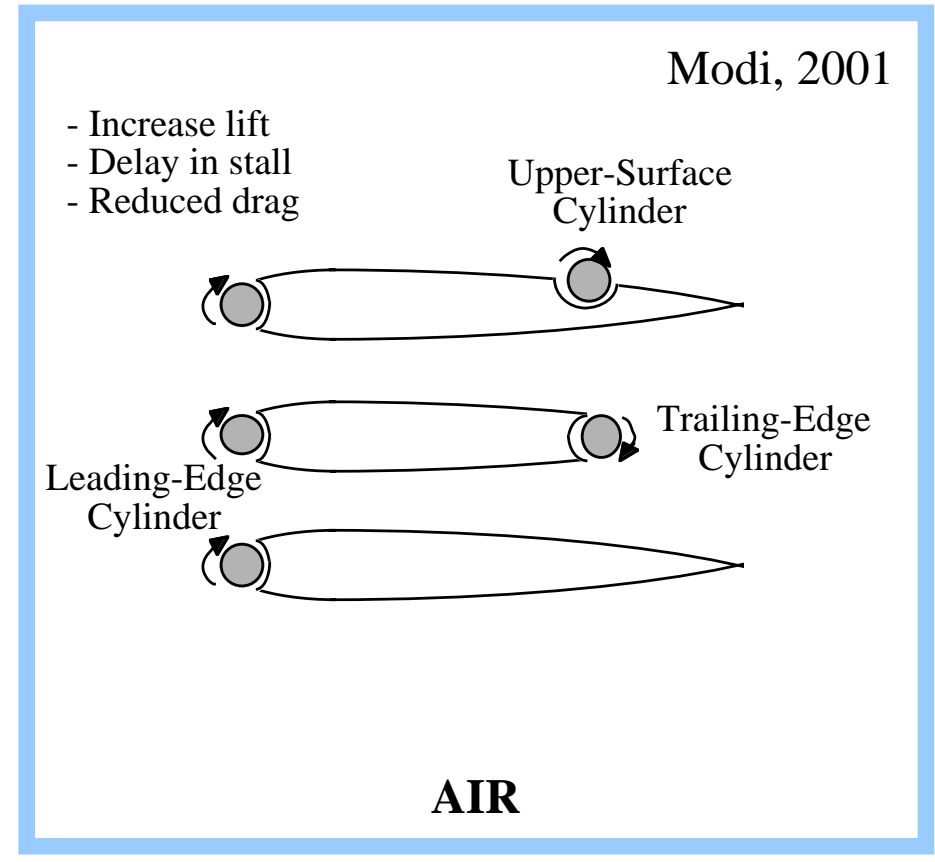

$>10 \%$ Drag Reduction

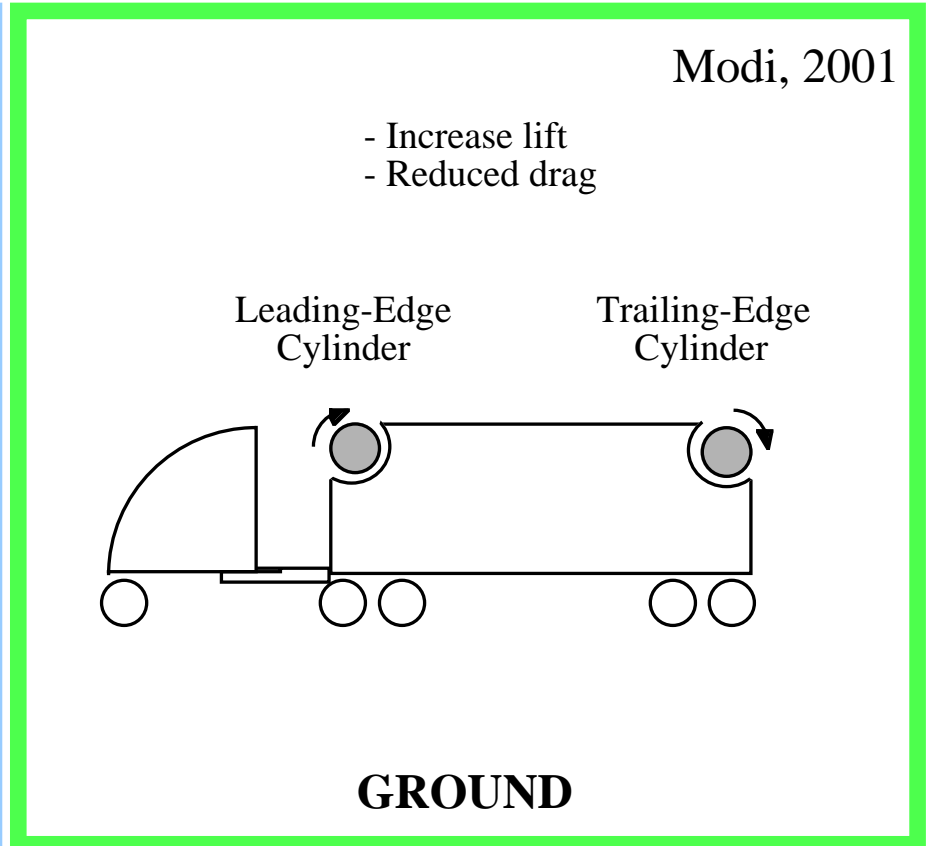

$>20 \%$ Drag Reduction

Figure 14. Rotating cylinder surface motion drag reduction technology. 
Englar, 2001

- Increase lift

- Delay in stall

- Reduced drag

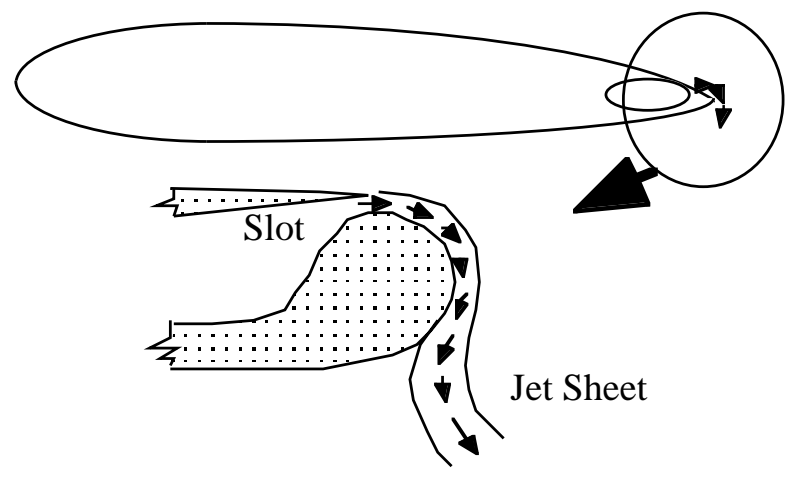

AIR

\section{$>10 \%$ Drag Reduction}

Englar, 2001

- Increase lift

- Reduced drag

Leading-Edge

Blowing

Trailing-Edge

Blowing

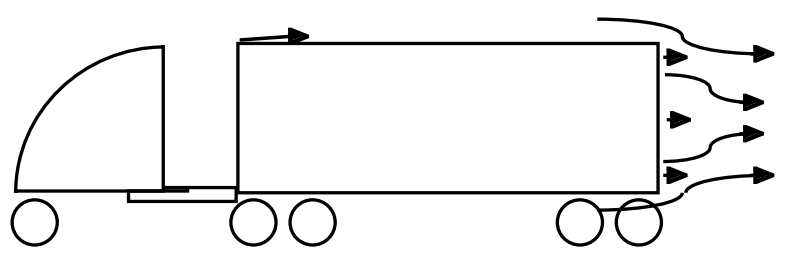

GROUND

$>20 \%$ Drag Reduction

Figure 15 Pneumatic blowing mass addition drag reduction technology.

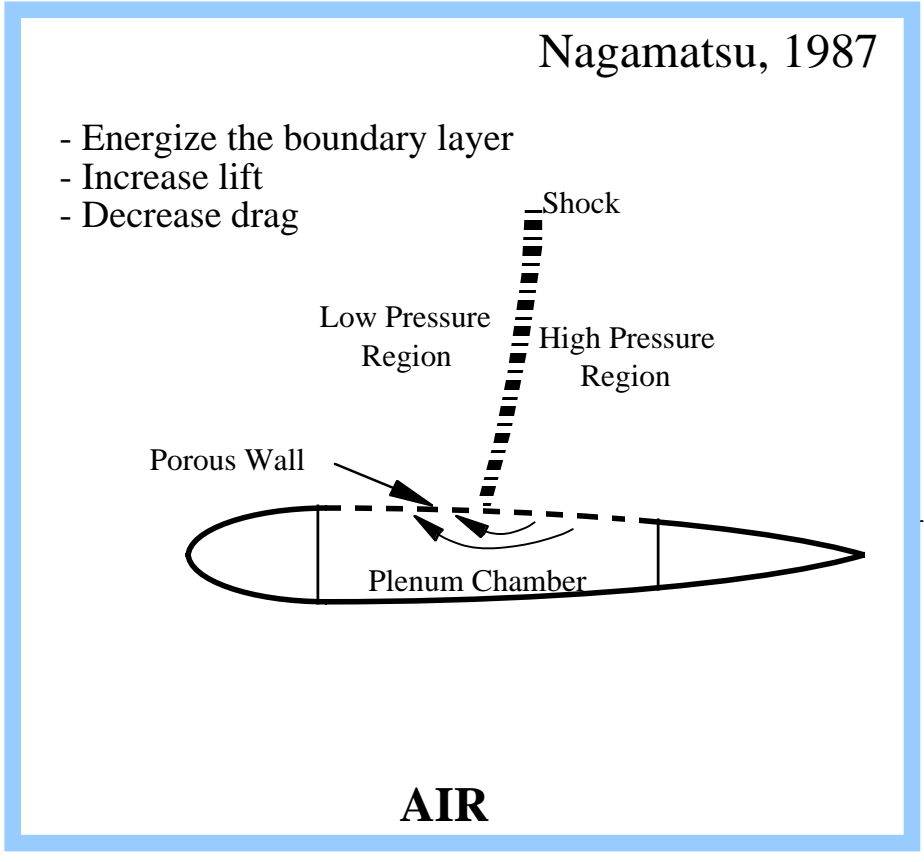

$>5 \%$ Drag Reduction

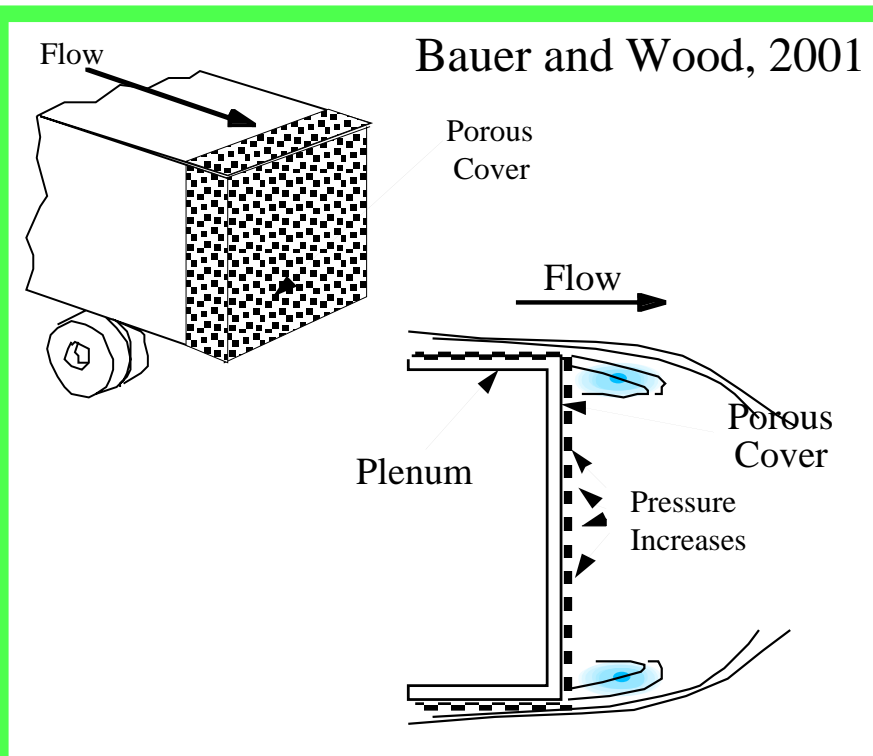

GROUND

\section{$>10 \%$ Drag Reduction}

Figure 16. Passive porosity surface permeability drag reduction technology. 


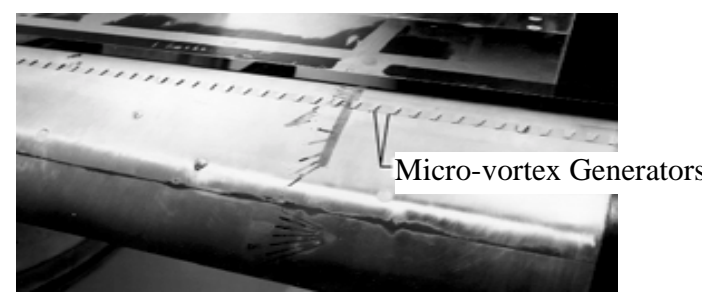

Vortex Generators

- No energy/mass addition

- Limited performance envelope

- Simple

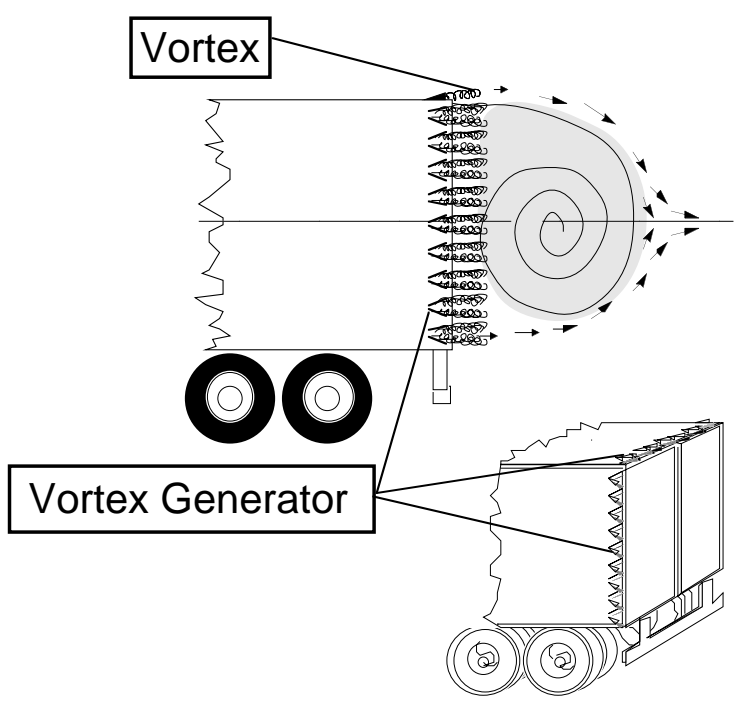

GROUND
AIR

$>20 \%$ Drag Reduction
$>5 \%$ Drag Reduction

Figure 17. Vortex generator flow field energizing drag reduction technology.

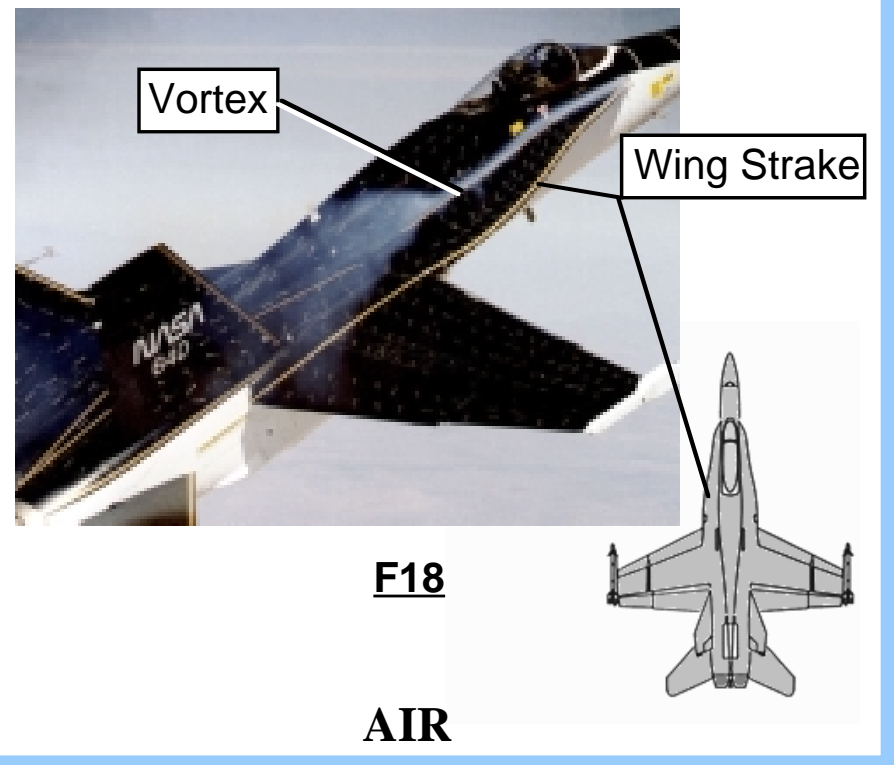

NA Drag Reduction

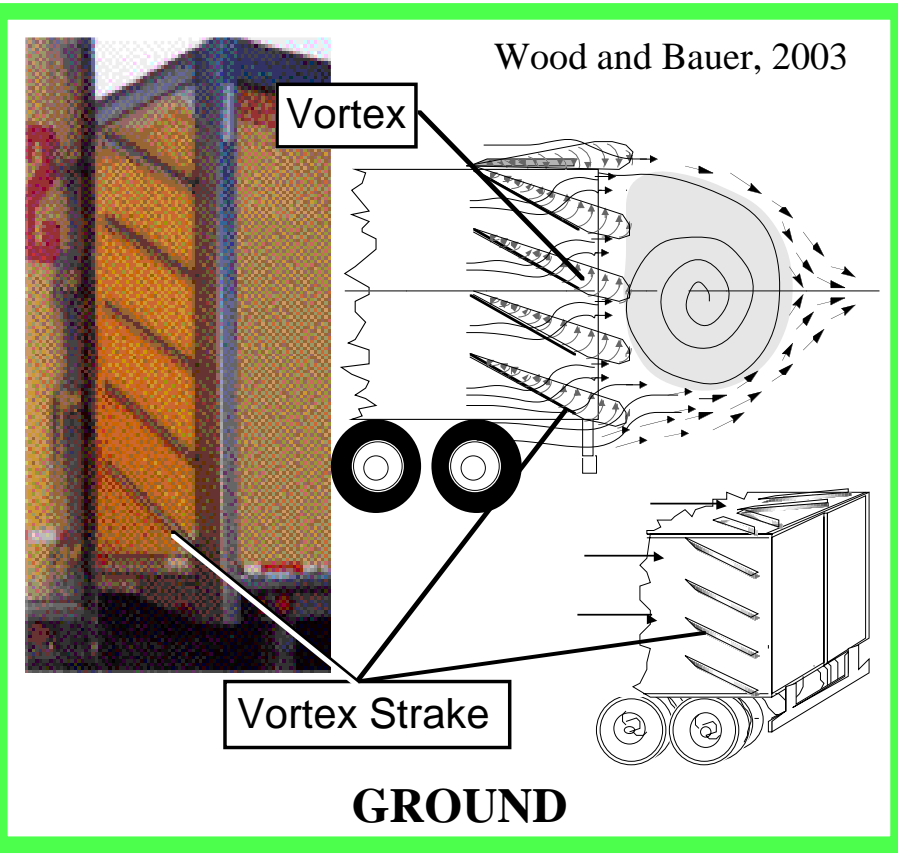

$>10 \%$ Drag Reduction

Figure 18. Vortex strake flow field energizing drag reduction technology. 

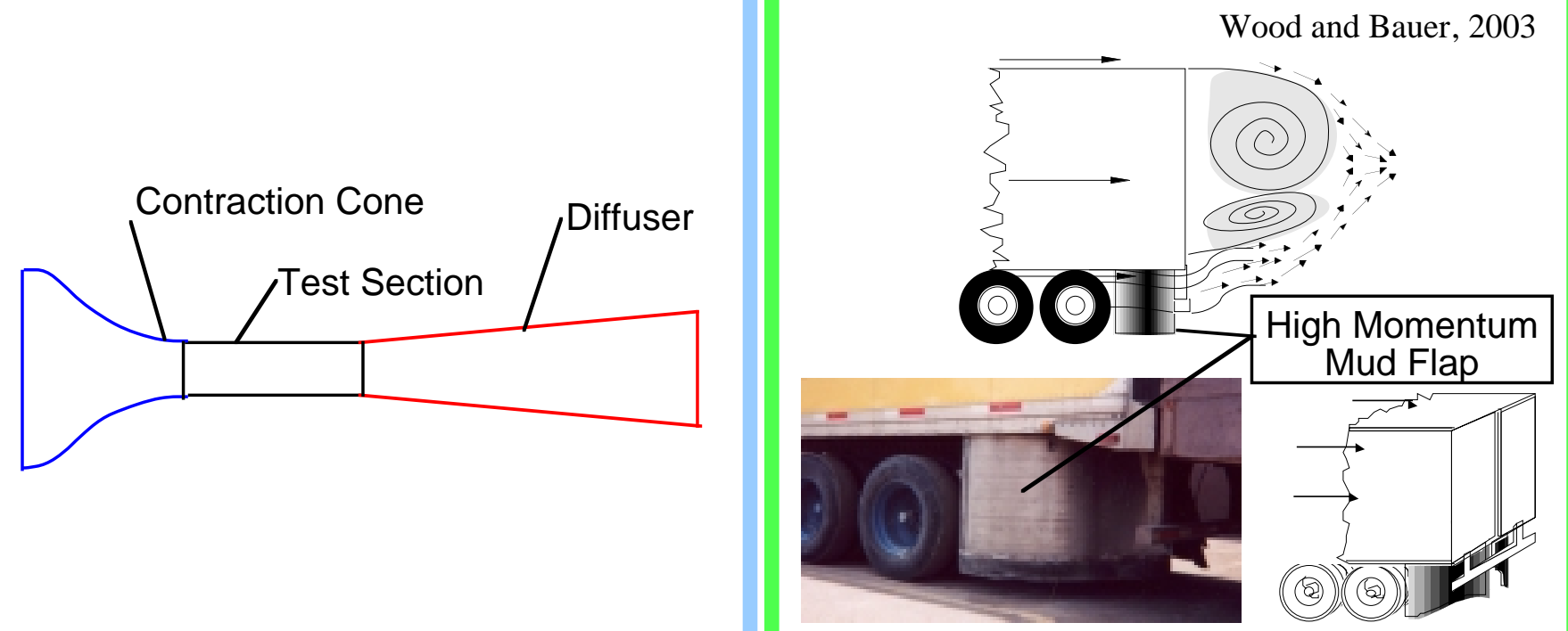

AIR

GROUND

NA Drag Reduction

$>10 \%$ Drag Reduction

Figure 19. Contraction cone based flow field energizing drag reduction technology.

\section{APPLICABILITY OF VARIOUS DRAG REDUCTION TECHNOLOGIES}

\begin{tabular}{|c|c|c|c|}
\hline Technology & Heavy Trucks & Light Trucks & Automobiles \\
\hline $\begin{array}{c}\text { Surface Shape: } \\
\text { Attached Flow }\end{array}$ & $\sqrt{ }$ & & \\
\hline $\begin{array}{c}\text { Surface Shape: } \\
\text { Separated Flow }\end{array}$ & $\sqrt{ }$ & & \\
\hline Surface Motion & $\sqrt{ }$ & \\
\hline Surface Permeability & $\sqrt{ }$ & \\
\hline Mass Addition & $\sqrt{ }$ & & \\
\hline Energy Addition & $\sqrt{ }$ & & \\
\hline
\end{tabular}

Figure 20. Drag reduction technology vehicle class application matrix. 
TIME FOR RETURN ON INVESTMENT, Years

\begin{tabular}{|l|c|c|c|}
\hline \multicolumn{1}{|c|}{ Technology } & Heavy Trucks & Light Trucks & Automobiles \\
\hline $\begin{array}{c}\text { Surface Shape: } \\
\text { Attached Flow }\end{array}$ & $<1$ & $<1$ & $<1$ \\
\hline $\begin{array}{c}\text { Surface Shape: } \\
\text { Separated Flow }\end{array}$ & $<1$ & $<1$ & $<1$ \\
\hline Surface Motion & $>2$ & $>2$ & \\
\hline Surface Permeability & $>2$ & $<2$ & $<1$ \\
\hline Mass Addition & $<2$ & $<1$ & $<$. \\
\hline Energy Addition & $<1$ & $<$ & $<$ \\
\hline
\end{tabular}

Figure 21. number of years for return on investment for each drag reduction technology and vehicle class.

INCREASE IN FUEL ECONOMY, \%

\begin{tabular}{|l|c|c|c|}
\hline Technology & Heavy Trucks & Light Trucks & Automobiles \\
\hline $\begin{array}{c}\text { Surface Shape: } \\
\text { Attached Flow }\end{array}$ & Industry Standard & Industry Standard & Industry Standard \\
\hline $\begin{array}{c}\text { Surface Shape: } \\
\text { Separated Flow }\end{array}$ & $10-15 \%$ & $5-7 \%$ & $2-5 \%$ \\
\hline Surface Motion & & & \\
\hline Surface Permeability & & & \\
\hline Mass Addition & $5-10 \%$ & $5-7 \%$ & $2-5 \%$ \\
\hline Energy Addition & $15-25 \%$ & $10-14 \%$ & $4-10 \%$ \\
\hline TOTAL & $15 \%$ & & \\
\hline
\end{tabular}

Figure 22. percent increase in fuel economy for each drag reduction technology and vehicle class. 